\title{
Ternary rhythm and the lapse constraint*
}

\author{
Nine Elenbaas \\ René Kager \\ Utrecht University
}

\section{Introduction}

Ternary rhythmic systems differ from binary systems in stressing every third syllable in a word, rather than every second. Consider the following examples from Cayuvava (Key 1961), where stress is on every third syllable counting from the end of the word:
(1) a. à.ri.hi.hí.be.e 'I have already put the top on'
b. ma.rà.ha.ha.é.i.ki 'their blankets'
c. i.ki.tà.pa.re.ré.pe.ha 'the water is clean'

Ternary rhythm is well-established for only a small group of languages, including Chugach Alutiiq, Cayuvava and Estonian, and possibly Winnebago. Nevertheless the stress patterns of these languages are sufficiently complex to warrant an ongoing debate about the implications for metrical theory (see Prince 1980, Levin 1985, 1988, Halle \& Vergnaud 1987, Halle 1990, Hammond 1990, Dresher \& Lahiri 1991, Rice 1992, Hewitt 1992, Kager 1993, 1994, Halle \& Idsardi 1995, Hayes 1995, Ishii 1996, Elenbaas 1999, among others).

The reason for a fresh look at ternarity is the rise of Optimality Theory (henceforth OT; Prince \& Smolensky 1993, McCarthy \& Prince 1993a), a theory abandoning most devices on which rule-based accounts of ternarity were based. It abandons serial derivations and together with it directional foot assignment, a core device in parametric theories of word stress, as well as special parsing modes for ternary rhythm (Weak Local Parsing; Hayes 1995). Derivational mechanisms and parameters are replaced by universal and violable constraints, stating well-formedness on output forms, and ranked in language-particular hierarchies.

The issue then arises whether OT is able to predict the ternary patterns in a descriptively adequate fashion. The first goal of this paper is to argue

* This paper is partly based on Kager (1994), an unpublished manuscript, and on Chapters 4 and 7 of Elenbaas (1999). We are grateful to Jan Don, Bruce Hayes, Curt Rice and Wim Zonneveld for their input to these earlier works, and also to the associate editor for commenting on an earlier version of this paper. 


\section{Nine Elenbaas and René Kager}

that adequate and insightful analyses are indeed possible in OT for two ternary stress languages: Cayuvava and Chugach Alutiiq. We argue that these analyses require no ternarity-inducing mechanisms, such as ternary feet or special parsing modes. Instead ternarity emerges by LICENSING, involving interactions of the anti-lapse constraint * LAPSE (banning long sequences of unstressed syllables; Selkirk 1984) with standard footalignment constraints (AlL-FT-X, Align-Y; McCarthy \& Prince 1993b). Our analysis incorporates Ishii's (1996) insight that ternarity is a kind of underparsing, which is licensed by an anti-lapse constraint, and induced by standard foot alignment.

Naturally, the step from rule-based theory to OT has repercussions in wider areas, such as representation. Upon reaching the goal of descriptive adequacy in the analysis of ternarity, the next issue promptly arises, concerning the explanatory adequacy of analytic tools. Our second goal is to make a contribution to an ongoing debate on the proper statement of the anti-lapse constraint, on which an adequate account of ternarity crucially depends. Two formats will be considered: a RHYTHMIC format, prohibiting long strings of weak beats on the grid (*LAPSE; Selkirk 1984), and a PARSING-based format, prohibiting strings of unparsed syllables (PARSE-2; Kager 1994). We will argue that the grid-based format is superior, both in terms of broad cross-linguistic coverage, and restrictiveness of typology. This will be established by detailed analyses of ternary languages of two kinds: those involving systematic ternarity (Cayuvava, Chugach), and those displaying occasional ternarity (Sentani, Finnish). Factorial typologies of grid-based and parsing-based anti-lapse constraints will be compared, resulting in a severe overgeneration by the latter.

Our final goal is to show that our rhythmic theory, couched in an OT framework, severely restricts the descriptive power of metrical theory, more so than RULE-BASED parametric theory. Again the argument will involve factorial typology: the range of ternary systems predicted by parametric theory is wider than that predicted by OT, under identical representational assumptions. Overgeneration by rule-based theory is due to its strictly serial character, and its resulting blindness to the output metrification, where the rhythmic effects of syllable parsing (foot assignment) and underparsing (syllable skipping and extrametricality) become apparent.

The organisation of this paper is as follows. Remaining subsections of $\$ 1$ sketch the OT analysis of binary rhythm, introducing the standard constraints pertaining to foot size, parsing syllables into feet, and foot alignment. $\$ 2$ generalises this approach to ternarity by an analysis of Cayuvava stress which involves no extra tools but the rhythmic anti-lapse constraint *LAPSE (Selkirk, 1984, Elenbaas 1999), banning long sequences of weak beats. We discuss, and reject, various alternative analyses of Cayuvava. One analysis, based on the foot-repulsion constraint ${ }^{*} \mathrm{FTF}_{\mathrm{T}}$ (Kager 1994), is rejected for its lack of independent motivation; we postpone the typological arguments against it to $\$ \S 3$ and 5. Another analysis, using a parsing-based anti-lapse constraint (PARSE-2; Kager 
Ternary rhythm and the lapse constraint 275

1994, Ishii 1996) is rejected for the ill-motivated representational assumptions it implies. $\S 3$ analyses ternarity in Chugach Alutiiq by a minimal reranking of the set of constraints used for Cayuvava. Next, $\$ \$ 4$ and 5 strengthen the case for *LAPSE on language-specific and typological grounds. $\$ 4$ offers an argument for the grid-based statement of *LAPSE on the basis of Sentani, a bounded stress language featuring occasional ternary intervals. Rather strikingly, Sentani allows feet of opposite dominance within a single word, offering us a chance to test grid-based and parsing-based formats of the anti-lapse constraint. Finnish (another language with occasional ternary intervals) provides additional evidence that *LAPSE is not a ternarity-specific tool, but rather a constraint broadly licensing rhythmically bounded intervals. $\S 5$ presents a typological argument for * LAPSE, arguing that it offers a restrictive factorial typology. In comparison, the factorial typology of its parsing-based competitor PARSE-2 predicts non-directional patterns, completely lacking from stress systems currently known. We end the paper by considering the factorial typology of parametric rule-based theory, and the causes of its overgeneration. Finally, $\$ 6$ offers conclusions.

\subsection{Binary rhythm in rule-based theory}

Many languages display a perfect rhythmic alternation of stressed and unstressed syllables. Universally, alternation is DIRECTIONAL, that is, oriented with respect to either the end or the beginning of the word. Pintupi (2a), for example, has rightward binary rhythm : the initial syllable and every following alternate non-final syllable are stressed (Hansen \& Hansen 1969). A leftward pattern occurs in Warao (2b), where stress falls on the penult and on every alternating syllable preceding it (Osborn 1966).

$$
\begin{aligned}
& \text { (2) a. }[(\dot{\sigma} \sigma)(\grave{\sigma} \sigma)(\grave{\sigma} \sigma)(\grave{\sigma} \sigma) \sigma] \text { yúma_tìnkamàrat'ù }{ }^{\dagger} \text { aka 'because of mother- } \\
& \text { b. }[\sigma(\grave{\sigma} \sigma)(\grave{\sigma} \sigma)(\grave{\sigma} \sigma)(\dot{\sigma} \sigma)] \text { enàhoròahàkutái 'the one who caused } \\
& \text { him to eat' }
\end{aligned}
$$

Rule-based metrical theory (Hayes 1980, 1995, Halle \& Vergnaud 1987) models binary rhythm on the basis of three parametric choices. First, selection of the Fоот from the universal inventory. Pintupi and Warao both select head-initial feet (TROCHEES). Secondly, specification of whether foot construction is iterative or non-iterative. Both Pintupi and Warao have ITERATIVE patterns, parsing the maximal number of syllables into well-formed feet. In Hayes (1995), feet must be binary in order to be wellformed, so that one syllable remains unparsed in words with an odd number of syllables. The edge at which this occurs (the right edge in Pintupi, the left edge in Warao) is controlled by a third parameter, governing the DIRECTION of foot construction. Here Pintupi differs from Warao : footing is rightward (starting at the left edge) in Pintupi, leftward (starting at the right edge) in Warao. In sum, a rule-based theory of binary rhythm uses three parameters: foot type, iterativity and directionality. 


\section{Nine Elenbaas and René Kager}

\subsection{Binary rhythm in constraint-based theory}

Rule-based theory is challenged by OT (Prince \& Smolensky 1993, McCarthy \& Prince 1993a, b), a constraint-based theory abandoning serial derivations and rewrite rules. Instead, it defines phonological patterns in terms of harmony (or relative well-formedness of the output), as evaluated by constraints. Grammars are defined as language-particular rankings of a set of universal constraints. Constraints are violable, but violation must be minimal, and occurs only in order to avoid violation of higher-ranking constraints. The optimal candidate is selected from a (potentially infinite) set of output candidates, by strictly hierarchically ranked constraints. Selection involves recursive evaluation, starting at the top-marked constraints and proceeding by lower-ranked ones, until only one candidate remains.

In the domain of metrical phonology, OT has had to meet the challenge of defining a non-derivational counterpart of the rule-based notion of Directional foot construction. McCarthy \& Prince (1993b) show that this is indeed possible, elaborating an idea which they attribute to Robert Kirchner. Their theory uses three constraints, involving binary foot size (FTBIN), exhaustive parsing of syllables by feet (PARSE- $\sigma$ ) and the vicinity of feet with respect to an edge of the Prosodic Word (ALL-FT-X). We will exemplify this theory on the basis of Pintupi. Recall that Pintupi foot parsing tilts towards the left edge of the PrWd. In the examples below this is apparent from forms that have an odd number of syllables (3a, c, e, f):

(3) a. $[(\dot{\sigma} \sigma) \sigma]$

b. $[(\dot{\sigma} \sigma)(\dot{\sigma} \sigma)]$

c. $[(\dot{\sigma} \sigma)(\grave{\sigma} \sigma) \sigma]$

d. $[(\dot{\sigma} \sigma)(\grave{\sigma} \sigma)(\grave{\sigma} \sigma)]$

e. $[(\dot{\sigma} \sigma)(\grave{\sigma} \sigma)(\grave{\sigma} \sigma) \sigma]$

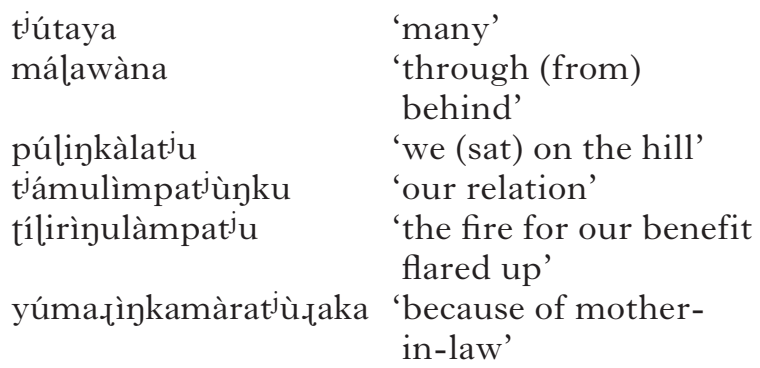

Deriving this foot distribution involves two notions typical of OT: CONSTRAINT INTERACTION and MINIMAL VIOLATION. The set of interacting constraints (Prince \& Smolensky 1993, McCarthy \& Prince 1993b) is stated as (4):

(4) a. FTBIN

Feet must be binary under syllabic or moraic analysis.

b. Parse- $\sigma$

All syllables must be parsed by feet.

c. All-FT-L

Align (Ft-L, PrWd-L)

'The left edge of every foot coincides with the the left edge of some PrWd.' 
Ternary rhythm and the lapse constraint 277

These constraints are potentially in conflict, and therefore must be ranked. First, the maximal parsing by binary feet is achieved by the ranking FTBIN $\gg$ PARSE- $\sigma$. When foot binarity is a top priority, a word with an odd number of syllables cannot be parsed exhaustively, since that would create non-binary feet. But even though PARSE- $\sigma$ is necessarily violated, its violation must be minimal. Therefore all parsings are rejected that contain more than a single unparsed syllable, the minimal violation. The ranking FTBIN $\gg$ PARSE- $\sigma$ enforces a maximal parse of PrWd into binary feet roughly an alternating pattern.

Orientation towards the left edge is implemented by ALL-FT-L (4c), a constraint stating the (surprisingly strong) requirement that every foot stand in the initial position of the PrWd. If ALL-FT-L were undominated (that is, if it were surface-true), no candidates with multiple feet would ever be selected. That is, for every candidate with multiple feet, a better one is always available that has a single initial foot. However, All-Ft-L cannot be undominated in Pintupi, precisely because the language displays rhythmic alternation, and hence enforces multiple feet per word. Instead ALL-FT-L exerts its influence in a more subtle way, by an interaction with PARSE- $\sigma$. When dominated by PARSE- $\sigma$, the role of AlLFT-L becomes restricted to selecting the candidate that minimally violates it. This is the one in which all feet are as close as possible to the designated PrWd edge, measured by numbers of syllables. We now have all evidence that is necessary for a complete ranking of all three constraints:

\section{(5) Ranking for binary rhythm in Pintupi}

FTBIN $\gg$ PARSE- $\sigma \gg$ ALL-FT-L

Tableau (6) displays this interaction. In the column below AlL-FT-L, each violation mark denotes a distance of one syllable between some foot and the left PrWd edge (while spaces separate the violations of individual feet).

\begin{tabular}{|c|c|c|c|}
\hline /pulinkalatju/ & FTBIN & PARSE $-\sigma$ & ALL-FT-L \\
\hline 政 a. (pú.lin).(kà.la). $\mathrm{t}^{\mathrm{j}} \mathrm{u}$ & & * & 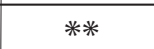 \\
\hline b. (pú.lin).ka.(là.t to u) & & * & ****! \\
\hline c. pu.(lín.ka).(là. $\left.\mathrm{t}^{\mathrm{j} u} \mathrm{u}\right)$ & & * & $* * * ! *$ \\
\hline d. (pú.lin).ka.la.t ${ }^{j} u$ & & *** !* & \\
\hline e. (pú.lin.ka.la.t $\mathrm{j}^{\mathrm{j}} \mathrm{u}$ ) & *! & & \\
\hline f. (pú.lin).(kà.la).(t $\left(\mathrm{t}^{\mathrm{j}} \mathrm{u}\right)$ & *! & & ******* \\
\hline
\end{tabular}

The ranking FTBIN $\gg$ PARSE- $\sigma$ is justified by rejection of candidates $(6 \mathrm{e}, \mathrm{f})$, both of which are exhaustively parsed (fully satisfying PARSE- $\sigma$ ), but fatally violate FTBIN by having feet that either exceed (6e) or fail to 


\section{Nine Elenbaas and René Kager}

achieve (6f) binarity. Next, the ranking PARSE- $\sigma \gg$ ALL-FT-L is apparent from the rejection of candidate (6d), which has only one foot, at the left edge. It thus satisfies ALL-FT-L, requiring every foot to be strictly initial in PrWd. Yet it fatally violates Parse- $\sigma$ by its three unparsed syllables, since other candidates $(6 \mathrm{a}-\mathrm{c})$ have fewer unparsed syllables. At this point, any remaining candidates $(6 a-c)$ have two binary feet differing only in their positions. ALL-FT-L, the next constraint down, selects as optimal the candidate with all feet as close as possible to the left edge. This is (6a), which incurs two violations, whereas the others $(6 \mathrm{~b}, \mathrm{c})$ have three and four violations, respectively.

In sum, languages with binary alternation share the constraint ranking (7), where ' $\mathrm{X}$ ' is an edge ( $\mathrm{L}$ or $\mathrm{R}$ ) specified in the foot-alignment constraint:

\section{(7) Binary rhythm}

FTBIN $\gg$ PARSE $-\sigma \gg$ AlL-FT-X

Let us now turn to ternary rhythm, and the extensions of ranking (7) which ternarity involves.

\section{Cayuvava}

Among ternary stress languages, Cayuvava (spoken in Bolivia) takes a special position in the sense that its ternarity is pure: all stresses are spaced exactly three syllables apart. The pattern, documented by Key (1961, 1967), can be stated as follows. Disyllabic words are stressed on the penult. In longer words stress falls on the antepenult and on every third syllable preceding it. Below we present the binary foot parsing predicted by the analysis of Hayes (1995) $:^{1}$

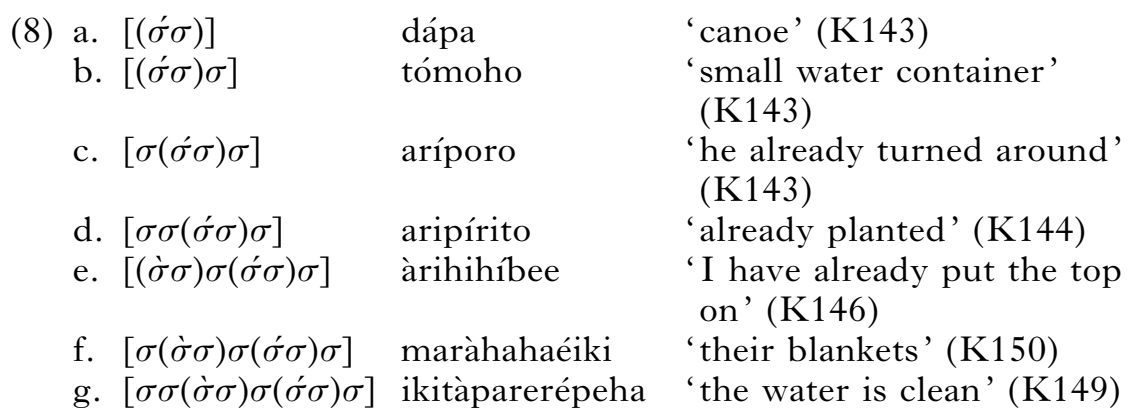

1 Cayuvava lacks a distinction in syllable weight. Adjacent vowels are syllabified as two syllables, rather than as a single diphthongal syllable. Key $(1961: 143)$ reports alternations between vowels and glides $([\mathrm{i}] \sim[\mathrm{j}],[\mathrm{u}] \sim[\mathrm{w}])$ which reflect a process of gliding. The stress representations are calculated on a pre-phonetic representation that does not include the effects of gliding. For example, the word iarau 'the night' (Key 1961 : 144) has two phonetic variants [járau] [iárau]. Finally, Key gives no examples of monosyllabic content words. We tentatively interpret this as evidence for a disyllabic word minimum. Page references in (8) are to Key (1961). 
Ternary rhythm and the lapse constraint 279

This ternary pattern was analysed in a rule-based framework by Levin (1985, 1988), Halle \& Vergnaud (1987), Dresher \& Lahiri (1991) and Hayes (1995). OT analyses were proposed by Kager (1994), Ishii (1996) and Elenbaas (1999). Before discussing the OT analyses, we briefly examine the rule-based analysis of Hayes (1995).

The central idea underlying Hayes' analysis is that ternary alternation can be analysed by binary feet in combination with a 'special' parsing mode. The final syllable is extrametrical, and the remaining syllables are footed while keeping a minimal distance between them:

(9) a. Final syllables are extrametrical (except in disyllabic words).

b. Assign trochees from right to left, under Weak Local Parsing.

Weak Local Parsing (WLP) is a parsing mode in which feet are not constructed back-to-back (cf. Strong Local Parsing), but are separated by one unparsed syllable. A syllable is skipped each time after a foot has been assigned. With binary feet, WLP yields inter-stress intervals of two syllables. This automatically accounts for the double upbeat observed in words of five or eight (i.e. $3 n+2)$ syllables, where the initial syllable remains unfooted even though there would have been room to form a binary foot. In (10), syllables skipped by WLP are underlined. A binary foot cannot be built over the first two syllables since the syllable [ki] is skipped (10b). Nor can a monosyllabic foot be built on the initial syllable [i], as this would violate the (universal) requirement of foot binarity $(10 \mathrm{c}){ }^{2}$

(10) a. i.ki.(tà.pa).re.(ré.pe).ha

b. *(i.ki).(tà.pa).re.(ré.pe).ha because of WLP

c. *(i).ki.(tà.pa).re.(ré.pe).ha because of ban on degenerate feet

This analysis will serve as a background for the discussion of two OT analyses of Cayuvava's strict ternarity. The first, which will eventually be rejected, is based on a direct counterpart of WLP, a foot-repulsion constraint ${ }^{*} \mathrm{FTF}_{\mathrm{T}}$ (Kager 1994). The second analysis uses a grid-based anti-lapse constraint (*LAPSE; Selkirk 1984, Elenbaas 1999). Unlike *FTFT, *LAPSE is not a constraint specifically designed to account for strict ternarity. Its scope is wider, generalising to bounded systems, including basically binary rhythmic systems with occasional ternarity, as we will show in $\$ 4$. In $\$ 2.3$ we discuss an alternative analysis by Ishii (1996), which, like ours, avoids *FTFT, but instead uses a parsing-based anti-lapse constraint (PARSE-2; Kager 1994).

\footnotetext{
2 An improvement over this analysis is due to Hammond (1990), who argues that Weak Local Parsing and extrametrically are functionally related: both produce parses in which binary feet are followed by a single unparsed syllable, either at the right edge of a word, or at the right edge of a foot. This is 'relativised extrametricality', that is relativised to a domain (foot or PrWd).
} 


\subsection{A foot-repulsion constraint: ${ }^{*} \mathrm{FTFT}_{\mathrm{T}}$}

An early OT analysis of Cayuvava (Kager 1994) assumed a counterpart of Hayesian WLP in the constraint *FTFT:

(11) ${ }^{*} \mathrm{FTFT}_{\mathrm{T}}$

Feet must not be adjacent.

At first sight, this foot-repulsion constraint is highly appropriate for Cayuvava-style ternarity. Intuitively, skipping a single syllable becomes a matter of constraint interaction: feet must not be adjacent, but otherwise parsing must be 'maximally dense', and oriented toward the right edge. Incorporating extrametricality in the form of Non-Finality (NON-FIN; Prince $\&$ Smolensky 1993), we arrive at the following ranking: ${ }^{3}$

\section{*FtFt, Non-Fin $\gg$ Parse- $\sigma \gg$ All-Ft-R}

The following tableau illustrates this analysis:

\begin{tabular}{|c|c|c|c|c|}
\hline /ikitaparerepeha/ & $*_{\mathrm{T}} \mathrm{F}_{\mathrm{T}}$ & Non-FIN & Parse $-\sigma$ & ALL-FT-R \\
\hline a. i.ki.(tà.pa).re.(ré.pe).ha & & & ****** & ****** \\
\hline b. i.(kì.ta).pa.re.(ré.pe).ha & & & ***** & ******* \\
\hline c. i.(kì.ta).pa.(ré.re).pe.ha & & & ***** & $* * * * * * * *$ \\
\hline d. i.ki.ta.pa.re.(ré.pe).ha & & & ******!* & * \\
\hline e. (ì.ki).(tà.pa).re.(ré.pe).ha & *! & & *** & * $* * * * * * * * * * *$ \\
\hline f. (ì.ki).ta.(pà.re).re.(pé.ha) & & $* !$ & ** & $* * * * * * * * *$ \\
\hline g. (ì.ki).(tà.pa).(rè.re).(pé.ha) & *!** & $* !$ & & 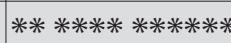 \\
\hline
\end{tabular}

Undominated ${ }^{*} \mathrm{~F}_{\mathrm{T}} \mathrm{F}_{\mathrm{T}}$ and NoN-FIN keep feet at a distance from each other and from the right edge, respectively. Among the candidates satisfying these requirements (13a-d), PARSE- $\sigma$ maximises the number of feet, ruling out a single-foot parsing (13d). (For words of eight syllables, the maximum number of feet is two; any parsings with more feet violate an undominated constraint, see $(13 \mathrm{e}-\mathrm{g})$.) Finally, what favours (13a) over $(13 \mathrm{~b}, \mathrm{c})$ is AlL-FT-R, pulling feet as far as possible to the right edge. Paradoxically, the leftward ternarity is due to a foot-alignment constraint referring to the right edge.

Note that this analysis is an exact OT analogue of the rule-based analysis of Hayes (1995). Each derivational mechanism (parameter setting) has a counterpart in the form of a ranked constraint:

${ }^{3}$ Essentially this is Kager's analysis, with his *PARSE- 2 constraint replaced by PARSE$\sigma$. We will shortly return to *PARSE- 2 . 
(14) Rule-based analysis

Extrametricality

Parsing mode (WLP)

Iterativity

Directionality
Ternary rhythm and the lapse constraint 281

OT analysis

$$
\begin{array}{ll}
\text { Non-Fin } & (\gg \text { Parse- } \sigma, \text { All-Ft }-R) \\
\text { *FtFT } & (\gg \text { Parse- } \sigma) \\
\text { Parse- } \sigma & (\gg \text { All-FT-R }) \\
\text { All-Ft-R } & (\gg \text { All-FT-L })
\end{array}
$$

The foot-repulsion constraint $*_{\mathrm{FTF}}$, although it straightforwardly captures the Cayuvava pattern, will nevertheless be rejected. As explained earlier, we aim at accounting for ternarity without ternarity-specific tools. Examples of ternarity-specific tools are: TERNARY FEET (Halle \& Vergnaud 1987, Levin 1988, Dresher \& Lahiri 1991, Hewitt 1992, Rice 1992); binary feet in combination with a SPECIAL PARSING MODE (Weak Local Parsing (Hayes 1995) or Relativised Extrametricality (Hammond 1990)); or, in the OT framework, any constraint whose only motivation is to capture strictly ternary patterns, such as the foot-repulsion constraint *FTFT.

This paper will present various types of evidence (from analysis of particular languages as well as typological) in favour of *LAPSE, an antilapse constraint that is not ternarity-specific, in the sense that it broadly enforces bounded rhythm, either binary or ternary. Immediately below, we will represent an analysis of Cayuvava based on *LAPSE, incorporating the insight from Ishii (1996) that ternarity arises from the interaction of foot alignment (ALL-FT-X) with an anti-lapse constraint. However, instead of the parsing-based anti-lapse constraint PARSE- 2 employed by Ishii, we will use *LAPSE, which has a purely rhythmic, grid-based format.

\subsection{A rhythmic anti-lapse constraint: *LAPSE}

We conceive of ternarity as a basically RHYTHмIC phenomenon, which involves an organisation of strong and weak beats in ternary intervals. Following Liberman (1975), Liberman \& Prince (1977), Prince (1983), Selkirk (1984) and many others, we assume that linguistic rhythm is represented as a hierarchical organisation of elements on the GRID. In bounded stress systems, strong beats are spaced one or two syllables apart, with an overall periodical tendency toward even spacing, either binary or ternary. Inter-stress distances are restricted both by upper and lower bounds. When inter-stress distance is too short, i.e. when two strong beats are adjacent, a rhythmic CLASH arises. When two strong beats are too far apart, there is a rhythmic LAPSE. Clashes and lapses are disfavoured in bounded stress systems.

Selkirk (1984: 52) proposes a Principle of Rhythmic Alternation, with an Anti-clash Provision and an Anti-lapse Provision.

(15) The Principle of Rhythmic Alternation

a. Anti-clash Provision

Every strong position on a metrical level $n$ should be followed by at least one weak position on that level. 


\section{Nine Elenbaas and René Kager}

b. Anti-lapse Provision

Any weak position on a metrical level $n$ may be preceded by at most one weak position on that level.

Here we will focus on the Anti-lapse Provision (15b), which disallows a sequence of three or more weak beats, for example:

$$
\begin{aligned}
& \begin{array}{lll}
x & x & \text { level } 1
\end{array} \\
& \begin{array}{lllllllll} 
& x & x & x & x & x & x & x & \text { level }
\end{array}
\end{aligned}
$$

Note that the Anti-lapse Provision broadly define the rhythmic margins of bounded systems, accommodating both binary and ternary styles of alternation. Selkirk (1984: 109) suggests that UG allows individual languages the option of a more stringent anti-lapse filter, banning any sequences of weak beats (including two weak beat sequences, which we might dub 'short lapses'). This option would be selected by languages enforcing strict metrical binarity, while ternary languages (which Selkirk does not actually discuss) would lack it.

We slightly adapt the statement of the Anti-lapse Provision as a constraint *LAPSE (Elenbaas 1999):

LAPSE

Every weak beat must be adjacent to a strong beat or the word edge.

This statement, although empirically non-distinct from the Anti-lapse Provision in evaluating output patterns, has the virtue of capturing the local nature of lapse avoidance. Evaluation of rhythmic well-formedness by *LAPSE involves no counting, not even up to two, as (implicit in 'at most') in the Anti-lapse Provision. All that *LaPse does is to check the linear adjacency of a weak beat with respect to rhythmic landmarks: either a strong beat or an edge. ${ }^{4}$ In this view, strong beats and edges become the LICENSORS of weak beats. As is well known, stressed syllables and word edges function as licensors in a range of phenomena in both segmental and metrical phonology (McCarthy \& Prince 1993b, Steriade 1995, Beckman 1997, Zoll 1997).

Naturally, the logical disjunction in the statement of (17) invites the question of whether * LAPSE is actually two constraints, rather than one. We hesitate to adopt this interpretation, as it is difficult to establish both branches in their own right by independent evidence. Under the first branch, 'every weak beat must be adjacent to a strong beat'. This is a cross-linguistically common restriction, satisfied by the strictly binary

\footnotetext{
${ }^{4}$ With undominated FTBIN, the following formulation of *LAPSE becomes empirically equivalent to (17): 'an unparsed syllable must be adjacent to a strong beat or the word edge'. (Thanks to the associate editor for pointing this out.) The hybrid nature of this constraint, referring to both parsing and the grid, does not falsify our claim that the anti-lapse constraint is crucially grid-based. This is because even in this hybrid constraint, there is reference to the grid (viz. a strong beat). A purely parsing-based anti-lapse constraint will be shown in $\$ 2.3$ not to be viable.
} 
Ternary rhythm and the lapse constraint 283

patterns attested in Warao (2b) and many other languages, as well as by the ternary pattern of Chugach Alutiiq $(\S 3)$. However, under the second branch, 'every weak beat must be adjacent to the word edge'. Assuming binarity of feet, this amounts to a ternary word template of a 'singlestress-plus-adjacent-weak-beats'. We know of no languages that unambiguously instantiate this size restriction (see Kager 1995 for discussion of word and root maxima defined in terms of feet).

(18) gives evaluations by *LAPSE of sequences of weak beats of different lengths, situated in different positions in the domain (initially, finally and medially), with the violating weak beat appearing in bold.

\begin{tabular}{|c|c|c|c|c|}
\hline 'valuat & $\begin{array}{l}\text { ions by } \text { * LAPSE } \\
\text { two weak beats }\end{array}$ & marks & three weak beats & marks \\
\hline Initial & {$\left[\begin{array}{lllll} & & x & \\
x & x & x & \ldots\end{array}\right.$} & $\checkmark$ & {$\left[\begin{array}{llllll} & & & & x \\
x & x & x & x\end{array}\right]$} & * \\
\hline Final & $\left.\ldots \begin{array}{ccc} & x & \\
\ldots & x & x\end{array}\right]$ & $\checkmark$ & $\left.\begin{array}{ccccc} & x & & \\
\ldots & x & x & x & x\end{array}\right]$ & * \\
\hline Medial & $\begin{array}{ll}\mathrm{x} & \mathrm{x}\end{array}$ & $\checkmark$ & $\mathrm{x} \quad \mathrm{x}$ & * \\
\hline
\end{tabular}

*LAPSE is violated by any sequence of three (or more) weak beats. This may seem tantamount to a ternarity-specific constraint, apparently undermining our central claim that systematic ternarity needs no ternarityspecific tools. However, as we will find in $\$ 4$, * LAPSE is motivated independently in the analysis of Sentani and Finnish, both bounded stress languages in which local ternary patterns appear due to various interacting constraints. Here *LAPSE will function to impose an upper limit on interstress intervals, instead of enforcing iterative ternary rhythm.

The relation between *LAPSE and ternarity is fairly indirect. *LAPSE broadly determines a minimum of rhythmic organisation on the grid, leaving room for both binarity and ternarity, the choice between which is made by other constraints. The general idea is that ternarity is a state in which lapses are avoided, while the number of feet is minimised. (In contrast, the number of feet is maximised under binarity, due to PARSE- $\sigma$.) Accordingly, *LAPSE must be undominated in ternary systems. But how can we achieve the minimisation of foot number?

We now turn to Ishii's (1996) idea that ternarity arises by the interaction of foot alignment and an anti-lapse constraint. Ishii's key observation (anticipated by Kager 1994: §3) is that ALL-FT-X reduces the number of feet to the bare minimum still allowed by the anti-lapse constraint. (We disregard the fact that Ishii's anti-lapse constraint is crucially different from ours; we return to this issue in §2.3.) The result is ternarity.

How does AlL-FT-X achieve this 'underparsing' goal? Any foot that is not strictly edge-adjacent violates the alignment constraint. Hence, the 
284 Nine Elenbaas and René Kager

more feet, the more violations will arise for ALL-FT-X. Consider the following trochaic parsings of a six-syllable string:

$$
\left.\begin{array}{rllllll}
(19) \text { a. } & \mathrm{x} & & \mathrm{x} & & \mathrm{x} & \\
\mathrm{x} & \mathrm{x} & \mathrm{x} & \mathrm{x} & \mathrm{x} & \mathrm{x} \\
(\sigma & \sigma) & (\sigma & \sigma) & (\sigma & \sigma
\end{array}\right)
$$

ALL-FT-L: $* * * * * *$ b. $x \quad x$ $\begin{array}{llllllllllllll}\mathrm{x} & \mathrm{x} & \mathrm{x} & \mathrm{x} & \mathrm{x} & \mathrm{x}\end{array}$ $\left(\begin{array}{llll}\sigma & \sigma\end{array}\right) \sigma\left(\begin{array}{ll}\sigma & \sigma\end{array}\right) \sigma$

ALL-FT-L: ***

Both satisfy *LAPSE, but parsing (19a) achieves this by having three feet, while parsing (19b) is more economical, having two feet only. The maximally dense parsing violates ALL-FT-L to a larger extent (incurring six marks) than the less dense parsing (which incurs three marks). This is at the expense of exhaustive parsing, motivating the partial ranking ALLFT-X $\gg$ PARSE- $\sigma .^{5}$

This is the core mechanism: ternarity, understood as an underparsing effect, is due to the following constraint interaction:

(20) Ranking for ternarity

$*$ LAPSE $\gg$ All-FT-X $\gg$ Parse $\sigma$

Let us now see how this works in the analysis of Cayuvava. We first consider words of length $3 n$ syllables. The tableau in (21) shows the effect of *LAPSE for a six-syllable word.

\begin{tabular}{|c|c|c|c|}
\hline /arihihibee/ & $*$ LAPSE & ALL-FT-L & PARSE- $\sigma$ \\
\hline a. (á.ri).hi.hi.be.e & $* ! * *$ & & $* * * *$ \\
\hline b. a.ri.(hí.hi).be.e & $* !$ & $* *$ & $* * * *$ \\
\hline c. (à.ri).(hí.hi).be.e & $* !$ & $* *$ & $* *$ \\
\hline \multirow{2}{*}{ d. (à.ri).hi.(hí.be).e } & & $* * *$ & $* *$ \\
\hline e. (à.ri).hi.hi.(bé.e) & $* !$ & $* * * *$ & $* *$ \\
\hline f. a.(rì.hi).hi.(bé.e) & & $* * * *$ ! $*$ & $* *$ \\
\hline g. (à.ri).(hì.hi).(bé.e) & & $* * * *$ ! $* *$ & \\
\hline
\end{tabular}

Observe the underparsing effect caused by ALL-FT-L: since its degree of violation is directly proportional to the sum of violations for individual feet, this constraint exerts pressure to minimise the number of feet. Foot number cannot drop below the bare minimum guaranteed by *LAPSE, however. The net result of the ranking *LAPSE $\gg$ ALL-FT-X is a ternary pattern.

Let us discuss some individual candidates to support this conclusion. First, any single-foot candidates $(21 \mathrm{a}, \mathrm{b})$ violate *LAPSE. Even a two-foot parse offers no guarantee for satisfying *LAPSE. For example, $(21 \mathrm{c}, \mathrm{e})$ violate *LAPSE due to their dis-rhythmic patterning of beats. Among the

5 The observation that ALL-FT-X prefers ternary over binary parsings is due to Kager (1994: 13). 
Ternary rhythm and the lapse constraint 285

three candidates that satisfy *LAPSE, the maximally dense three-foot parse (21g) is excluded by ALL-FT-L. When comparing two-foot parsings (21d) and (21f), a second major role of ALL-FT-L becomes apparent - regulating directionality of footing. ALL-FT-L pulls feet maximally to the left edge of the word, selecting the ternary form (21d).

The ranking arguments on the basis of six-syllable forms are spelled out below (where ' $\succ$ ' should be read as 'is more harmonic than'):

\section{(22) Ranking arguments}
a. *LAPSE $\gg$ All-FT-L
(à.ri).hi.(hí.be).e $\succ$ (á.ri).hi.hi.be.e
b. All-Ft $-\mathrm{L} \gg$ PARSE- $\sigma$ (à.ri).hi.(hí.be).e $\succ$ (à.ri).(hì.hi).(bé.e)

The pattern of words with $3 n+1$ syllables is predicted equally straightforwardly. For a seven-syllable word, the minimal number of feet that is necessary to satisfy * LAPSE is two. (Generally, the number of feet required for a word of $3 n+1$ syllables equals $n$.) Foot number is kept at a bare minimum by ALL-FT-L, penalising overparsing (see the three-foot candidate $(23 g))$.

\begin{tabular}{|c|c|c|c|}
\hline /marahahaeiki & $*$ LAPSE & ALL-FT-L & PARSE- $\sigma$ \\
\hline a. (má.ra).ha.ha.e.i.ki & $* ! * * *$ & & $* * * * *$ \\
\hline b. ma.ra.(há.ha).e.i.ki & $* ! *$ & $* *$ & $* * * * *$ \\
\hline r. ma.(rà.ha).ha.(é.i).ki & & $* * * * *$ & $* * *$ \\
\hline d. ma.ra.(hà.ha).(é.i).ki & & $* * * * * * !$ & $* * *$ \\
\hline e. ma.ra.(hà.ha).e.(i.ki) & & $* * * * * * * *$ & $* * *$ \\
\hline f. (mà.ra).ha.(há.e).i.ki & $* !$ & $* * *$ & $* * *$ \\
\hline g. (mà.ra).(hà.ha).(é.i).ki & & $* * * * * * !$ & $*$ \\
\hline
\end{tabular}

The upshot of the examples seen thus far is this: beats are pulled as far to the left edge as is allowed by the anti-lapse constraint, resulting in a pattern where beats fall on every third syllable counting from the end.

The question then arises of what happens in the case of words with $3 n+2$ syllables, where there is enough room to accommodate an initial foot. This initial foot actually seems to come for free, as it does not cause extra violations of ALL-FT-L, as compared to the strictly ternaryrhythmic candidate:

(24) Incorrect prediction due to All-FT-L $\gg$ Parse- $\sigma$

(i.ki).(tà.pa).re.(ré.pe).ha $\succ$ i.ki.(tà.pa).re.(ré.pe).ha

Since there is a tie on AlL-FT-L for these candidates, we predict the threefoot parsing to be optimal, due to a minimal violation of PARSE- $\sigma$.

In fact, a minor modification of the hierarchy produces the double underparsing in words of length $3 n+2$ syllables. CoN contains an (independently motivated) foot-alignment constraint militating against the initial foot. This constraint, AlL-FT-R, evaluates the position of all 


\section{Nine Elenbaas and René Kager}

feet with respect to the right edge: the more feet, the more violations. Clearly an initial foot causes extra violations of ALL-FT-R. This constraint seals the fate of the lefthand candidate in (24) at the expense of violation of PARSE- $\sigma$. All it takes to achieve the initial underparsing effect is to insert All-Ft-R between All-Ft-L and PARSE- $\sigma$ in the ranking hierarchy.

\section{(25) Final ranking for Cayuvava}

*LAPSE $\gg$ AlL-FT-L $\gg$ AlL-FT-R $\gg$ PARSE- $\sigma$

This analysis is illustrated by the tableau in (26), which should now be self-explanatory:

\begin{tabular}{|c|c|c|c|c|}
\hline /ikitaparerepeha/ & *LAPSE & ALL-FT-L & AlL-FT-R & $\begin{array}{c}\text { PARSE- } \\
\sigma\end{array}$ \\
\hline a. i.(kì.ta).pa.(ré.re).pe.ha & $* !$ & * ***** & $* * * * * * *$ & ***** \\
\hline u b. i.ki.(tà.pa).re.(ré.pe).ha & & $* * * * * * *$ & $* * * * *$ & $* * * *$ \\
\hline c. (ì.ki).(tà.pa).re.(ré.pe).ha & & $* * * * * * *$ & * ****** $*$ ! ***** & ** \\
\hline d. (ì.ki).ta.(pà.re).re.(pé.ha) & & $\begin{array}{c}\text { **** } \\
* * * * * !\end{array}$ & **** $* * * * * *$ & *** \\
\hline e. (ì.ki).(tà.pa).(rè.re).(pé.ha) & & $\begin{array}{l}* * * * * * * \\
* * ! * * * * *\end{array}$ & ** ***** ****** & \\
\hline
\end{tabular}

The critical comparison is between candidates (26b) and (26c), which are identical in parsing except for the extra foot on the initial two syllables in (26c). Yet an initial foot does not incur extra violations of ALL-FT-L, resulting in a tie between both candidates on ALL-FT-L. There is an even lower-ranked constraint, however, for which the initial foot in (26c) incurs severe violations as compared to (26b). This is ALL-FT-R, selecting (26b) as the optimal candidate.

We now add the additional ranking arguments:

(27) Ranking arguments

$$
\begin{array}{ll}
\text { a. All-FT-L } \gg \text { ALL-FT-R } & \\
\quad \text { (àri.).hi.(hí.be).e } & \succ \text { a.(rì.hi).hi.(bé.e) } \\
\text { ma.(rà.ha).ha.(é.i).ki } & \succ \text { ma.ra.(hà.ha).e.(í.ki) } \\
\text { b. All-FT-R } \gg \text { PARSE- } \sigma & \\
\text { i.ki.(tà.pa).re.(ré.pe).ha } & \succ \text { (i.ki).(tà.pa).re.(ré.pe).ha }
\end{array}
$$

Active involvement of both AlL-FT-L and AlL-FT-R in the selection of the optimal candidate is a result typical of OT. These constraints make directly conflicting requirements, but still the domination of one by the other is not tantamount to the inactivity of the dominated constraint. Rather subtly, the dominated constraint (ALL-FT-R) is active precisely in the context where the dominating constraint (ALL-FT-L) is unable to force a decision. Activity of a dominated constraint illustrates a crucial difference between OT and parametric theory: constraints are not 'switched off', but will become active whenever there is a chance. 
Ternary rhythm and the lapse constraint 287

We will now briefly discuss an alternative analysis of Cayuvava proposed by Ishii (1996), who uses a foot-based anti-lapse constraint.

\subsection{A foot-based anti-lapse constraint: Parse-2}

As mentioned earlier, Ishii (1996) should be credited for the idea of using foot alignment as an underparsing mechanism to create ternary rhythm. However, Ishii's execution of this idea runs into difficulties, due to the particular choice of the anti-lapse constraint. Instead of the grid-based anti-lapse constraint * LAPSE that we have argued for in the previous section, Ishii assumes Kager (1994)'s foot-based constraint PARSE- $2:{ }^{6}$

(28) Parse-2

Of every two stress units one must be parsed into a foot.

PARSE-2 measures lapses not by constraining sequences of weak beats (as does *LAPSE), but by constraining sequences of unparsed syllables. Accordingly, initial weak-beat sequences are evaluated differently; compare (18) with (29):

(29) Evaluations by PARSE-2 (for trochaic parsing)

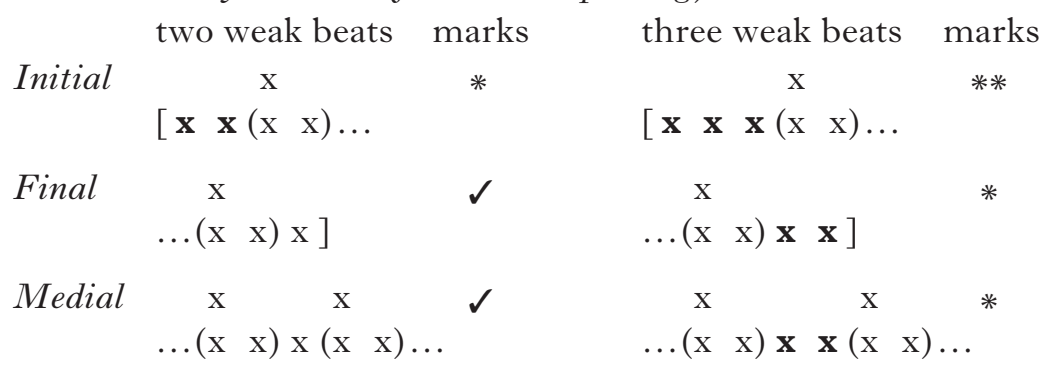

For a trochaic parsing, *LAPSE and PARSE- 2 produce identical evaluations in final and medial contexts. But evaluations crucially differ for an initial sequence of two weak beats, which is exactly the underparsing effect attested in words of length $3 n+2$ syllables (the double upbeat) in Cayuvava. This context amounts to a violation of PARSE-2, while it is tolerated by our grid-based *LAPSE. In Ishii's analysis, this implies that either some constraint dominates *PARSE-2 to enforce double underparsing, or that double upbeats require special assumptions about their representation. Either solution leads to severe complications, as we will see.

The core of Ishii's analysis consists of the following ranking: $:^{7}$

(30) Non-Fin, Parse-2 $\gg$ All-Ft-L $\gg$ Parse- $\sigma$

${ }^{6}$ Confusingly, Ishii refers to the foot-based anti-lapse constraint as *Lapse, whose formulation is identical to the PARSE- 2 constraint proposed in Kager (1994). To avoid confusion with the grid-based constraint defined above, we will refer to Ishii's constraint in analysis as PARSE-2.

7 Ishii assumes some unspecified constraint to trigger antepenultimate stress, which we equate with Non-Fin. 


\section{Nine Elenbaas and René Kager}

The undominated constraints exclude final feet and lapses, respectively. Ranked immediately below this we find the foot-alignment constraint AlL-FT-L, whose ranking above PARSE- $\sigma$ results in ternarity.

For words of length $3 n$ syllables (31) and $3 n+1$ syllables (32), the analysis runs fairly smoothly.

\begin{tabular}{|c|c|c|c|c|}
\hline /arihihibee/ & Non-Fin: PARSE-2 & ALL-FT-L & PARSE- $\sigma$ \\
\hline a. a.ri.hi.(hí.be).e & & $* ! *$ & $* * *$ & $* * * *$ \\
\hline b. (à.ri).(hí.hi).be.e & & $* !$ & $* *$ & $* *$ \\
\hline c. (à.ri).hi.(hí.be).e & & & $* * *$ & $* *$ \\
\hline d. a.(rì.hi).(hí.be).e & & & $* * * * !$ & $* *$ \\
\hline e. (à.ri).(hì.hi).(bé.e) & $* !$ & & $* * * * * *$ & \\
\hline
\end{tabular}

PARSE-2 rejects any single-foot parse (31a), as well as the two-foot parse with feet placed too far from the edge $((31 \mathrm{~b})$, the candidate otherwise preferred by ALL-FT-L). The underparsing effect due to ALL-FT-L cannot be observed in a six-syllable word, since undominated NoN-FIN already rules out (31e). Here the role of foot alignment remains restricted to selecting the two-foot form with feet pulled maximally to the left.

\begin{tabular}{|c|c|c|c|c|}
\hline /marahahaeiki & Non-Fin & PARse-2 & AlL-FT-L & PARSE- $\sigma$ \\
\hline a. ma.ra.ha.ha.(é.i).ki & & $* ! * *$ & $* * * *$ & $* * * * *$ \\
\hline b. (mà.ra).ha.(há.e).i.ki & & $* !$ & $* * *$ & $* * *$ \\
\hline c. (mà.ra).ha.ha.(é.i).ki & & $* !$ & $* * * *$ & $* * *$ \\
\hline d. ma.(rà.ha).ha.(é.i).ki & & & $* * * * *$ & $* * *$ \\
\hline e. (mà.ra).(hà.ha).(é.i).ki & & & $* * * * * * !$ & $*$ \\
\hline
\end{tabular}

This tableau (which omits any candidates violating Non-FIN) provides the ranking argument (anticipated above) for AlL-FT-L $\gg$ PARSE- $\sigma$. The two-foot parse (32d) with ternary rhythm has fewer violations of ALL-FT$\mathrm{L}$ than a three-foot parse (32e) with binary rhythm.

Thus far the analysis of Cayuvava is unproblematic, but (as mentioned above) words with length $3 n+2$ syllables, with their double upbeat, cause problems for Ishii's assumption that PARSE-2 is undominated. The challenge is to account for the double upbeat, and to that end two strategies may be considered: 'normal' constraint interaction or 'special' representational assumptions about metrical parsing. In the former case, PARSE-2 must be dominated by some constraint blocking an initial foot, but this strategy is destined to fail. Crucially, the method so successful in our analysis based on opposite-edge foot alignment (ALL-FT-R) does not work here. AlL-FT-R cannot be promoted over PARSE-2 so as to block initial feet, as this would produce single-foot parsings throughout. (Recall that foot alignment militates against any foot that is not strictly at the specified edge.) Moreover, any 'non-initiality' constraint ranked high enough to block an initial foot in words of $3 n+2$ syllables will also 
Ternary rhythm and the lapse constraint 289

(incorrectly) block it in words of $3 n$ syllables, precluding [(à.ri). hi.(hí.be).e].

Ishii thus pursues the second strategy of keeping PARSE- 2 undominated, making 'special' assumptions about the parsing of double upbeats. $\mathrm{He}$ argues for EXTRASYLLABICITY of the initial (C)V sequence in a $3 n+2$ word, so that in a double upbeat only one syllable remains unparsed.

(33) $\mathrm{CV} \sigma(\grave{\sigma} \sigma) \sigma(\dot{\sigma} \sigma) \sigma$

Extrasyllabicity violates PARSE-SEg ('all segments must be parsed by syllables'), although it is assumed that extrasyllable segments are 'normally' parsed by moras.

To enforce extrasyllabicity, Ishii introduces the following constraint:

(34) Non-Align-PrWd-L

The word does not begin with a foot.

Now consider the tableau of a form of $3 n+2$ syllables. Here candidate (35c), with an initial extrasyllabic (underlined boldface) vowel, is selected:

\begin{tabular}{|c|c|c|c|c|c|}
\hline /ikitaparerepeha/ & $\begin{array}{c}\text { PARSE- } \\
2\end{array}$ & $\begin{array}{c}\text { AlL- } \\
\text { FT-L }\end{array}$ & $\begin{array}{c}\text { Non-Align- } \\
\text { PRWD-L }\end{array}$ & $\begin{array}{c}\text { Parse- } \\
\sigma\end{array}$ & $\begin{array}{c}\text { PARSE- } \\
\text { SEG }\end{array}$ \\
\hline a. i.ki.(tà.pa).re.(ré.pe).ha & $* !$ & $\mu \mu \mu \mu \mu \mu \mu$ & & $* * * *$ & \\
\hline b. (ì.ki).(tà.pa).re.(ré.pe).ha & & $\mu \mu \mu \mu \mu \mu \mu$ & $* !$ & $* *$ & \\
\hline q c. i ki.(tà.pa).re.(ré.pe).ha & & $\mu \mu \mu \mu \mu \mu \mu$ & & $* * *$ & $*$ \\
\hline
\end{tabular}

Candidate (35a), the 'normally' syllabified analysis of a double upbeat, violates undominated PARSE-2. Therefore the choice is between (35b) and (35c), which have the same number of violations for ALL-FT-L. One aspect of this tableau deserves comments right here, relating to the unit for measuring ALL-FT-L violations. Ishii assumes that each extrasyllabic vowel has a mora, which ALL-FT-L treats on a par with the syllable as a counting unit. This assumption is motivated by the next tableau.

Tableau (36) evaluates candidates of a word of length $3 n$ syllables. This tableau shows two points. First, it now becomes clear why Non-AligNL must be dominated by AlL-FT-L. If Non-Align-PRWD-L were highranked, the incorrect candidate (36c) would be selected:

\begin{tabular}{|r|c|c|c|c|c|}
\hline \multicolumn{1}{|c|}{ /arihihibee/ } & PARSE-2 & All-FT-L & $\begin{array}{c}\text { Non-Align- } \\
\text { PrWD-L }\end{array}$ & PARse- $\sigma$ & $\begin{array}{c}\text { PARse- } \\
\text { SEG }\end{array}$ \\
\hline a. (à.ri).hi.(hí.be).e & & $\mu \mu \mu$ & $*$ & $* *$ & \\
\hline b. a.(rì.hi).(hí.be).e & & $\mu \mu \mu \mu !$ & & $* *$ & \\
\hline c. $\underline{\mathbf{a}}$ (rì.hi).(hí.be).e & & $\mu \mu \mu \mu !$ & & $*$ & $*$ \\
\hline
\end{tabular}

Second, this tableau shows why it is crucial that extrasyllabic moras are counted on a par with genuine syllables for measuring ALL-FT-L violations. If extrasyllabic moras were not counted, candidate (36c) would have one fewer violation of ALL-FT-L, making it a winner on the spot. 


\section{Nine Elenbaas and René Kager}

This analysis is problematic for various reasons. The main problem is that the assumption of left-edge extrasyllabicity to account for words with a double upbeat is ad hoc, as it lacks independent motivation in the phonology of Cayuvava. The source of this problem is the anti-lapse constraint used, PARSE-2, which Ishii assumes to be undominated in Cayuvava. This is avoided in our analysis, where *LAPse can stay undominated without special representational assumptions since it allows an initial upbeat of two syllables.

A second problem is that of the units in which ALL-FT-X violations are counted. In Ishii's analysis extrasyllabic segments are counted on a par with syllables in order to be able to select the correct candidate in words of $3 n$ syllables. This assumption is problematic, since segments should clearly not be counted when 'normally' parsed by syllables. Segment counting causes further complications in $3 n+2$ words starting with a CV sequence, where both segments must be extrasyllabic, while the $\mathrm{CV}$ sequence must nevertheless be counted as a single unit for ALL-FT-X violations.

The third problem relates to NoN-ALign-PRWD-L, the constraint disallowing word-initial feet, amounting to 'left-edge-extrametricality' (or non-initiality). Non-initiality constraints are highly unnatural in stress systems. A strong cross-linguistic tendency was observed by Hayes (1980, 1995) for stress systems to avoid final stress, whereas no cross-linguistic avoidance of initial stress occurs, certainly not in trochaic systems. In OT this asymmetry is expressed by the constraint NON-FIN, which exclusively refers to the right edge. Its unnatural left edge counterpart Non-AligN$\mathrm{PRWD}_{\mathrm{R}} \mathrm{L}$ is simply circumvented in our analysis, which uses ALL-FT-R, a constraint independently motivated for bounded stress systems. ${ }^{8}$

A final, less serious problem involves non-finality. Ishii's analysis requires a mechanism to enforce non-finality of the rightmost foot (Ishii fails to discuss this). In our analysis non-finality automatically follows from the independently motivated ranking, with * LAPSE undominated and ALL-FT-L ranked immediately below it. That is, foot alignment pulls the rightmost foot away from the right edge, but lapse avoidance prevents it from retracting further back than the antepenult. We will discuss the intersecting relation between *LAPSE and NON-FIN in $\S 5$.

\section{Chugach Alutiiq}

Like all other Yupik dialects, Chugach Alutiiq (henceforth Chugach) has iambic rhythm. Leer (1985) reports that in words consisting of light syllables only, stress falls on every syllable in position $3 n-1$ (i.e. $\sigma_{2}, \sigma_{5}$,

8 Ishii assumes that there must be some remedy against extrasyllabicity in words consisting of $3 n+1$ (like maràhahaéiki). He introduces constraints enforcing proper parsing of segments by syllables. However, since this has no empirical effect in terms of stress, we will leave this part of Ishii's analysis out of consideration. 
Ternary rhythm and the lapse constraint 291

etc.), as well as on the final syllable of any words of length $3 n+1$ (i.e. four, seven) syllables. Lefthand foot edges are detectable by their initial consonant, which is realised fortis, as indicated by boldface. This provides additional evidence for feet. ${ }^{9}$

(37) a. (mu.lú).kan

b. (a.kú).(ta.mék)

c. (ta.qá).ma.(lu.ní)

d. (a.kú).tar.(tu.nír).tuq

e. (ma.yár).su.(qu.tá).(qu.ní) 'if she takes a long time' (L87)

akutaq (a food; ABL SG) (L84)

'apparently getting done' (L89)

'he stopped eating akutaq' (L87)

'if he (REFL) is going to hunt porpoise’ (L113)

Leer marks no primary-secondary stress distinction, and we will follow his transcription here.

The ternary pattern of Chugach has been analysed in rule-based theory with ternary feet (Halle 1990, Rice 1992, Hewitt 1992), whereas Hayes $(1995)^{10}$ and Kager (1993) combine binary feet and Weak Local Parsing. Hayes predicts the pattern in (37) by means of rightward iambs and WLP:

\section{(38) Rule set predicting Chugach footing}

a. Assign iambs from left to right, under Weak Local Parsing.

b. Footing is persistent.

By persistent footing (38b), any pairs of syllables that are still unparsed after directional foot assignment must be footed:

(ma.yár).su.(qu.tá).qu.ni $\rightarrow$ (ma.yár).su.(qu.tá).(qu.ní)

Persistent footing is a parametric option, one which Chugach selects, while Cayuvava clearly does not (as we infer from words of $3 n+2$ syllables, see previous section). In $\$ 3.1$ we will see how this parametric choice simply translates as a constraint reranking without any need for additional tools except a well-motivated foot-alignment constraint.

\subsection{Persistent footing as a reranking}

Earlier OT analyses of Chugach were proposed by Green \& Kenstowicz (1995), who used a foot-repulsion constraint * FTFT, and Ishii (1996), who pursued the idea that ternarity is due to interaction of ALL-FT-X and an anti-lapse constraint. Ishii's analysis, which is very similar to ours except from a difference in the anti-lapse constraint, will be reviewed in §3.2.

9 Leer (1985: 84) notes 'two major distinguishing characteristics of the fortis consonant: complete lack of voicing with voiceless consonants (stops and voiceless fricatives), and preclosure'. Because of space limitations, we ignore the fact that vowels in stressed open syllables are lengthened (Hayes 1995, Kager 1993). Page references in (37) are to Leer (1985).

10 Draft versions of Hayes' book were circulating from 1991 on. Differences between Hayes' and Kager's analyses involve the definition of the iambic foot. These do not affect the metrification of words with only light syllables, however. 


\section{Nine Elenbaas and René Kager}

As a preliminary to the analysis, we observe that Chugach footing is left-to-right, whereas Cayuvava has the opposite directionality. We therefore expect Chugach's ternarity to be due to the following core interaction of constraints:

$$
* \text { LAPSE } \gg \text { All-FT-R } \gg \text { PARSE }-\sigma
$$

This interaction is identical to the core of the Cayuvava hierarchy in (20), the only difference residing in the edge specified in the foot-alignment constraint.

The question promptly arises how Hayes' foot-persistence parameter translates into a difference in ranking between Cayuvava and Chugach. We will show that a simple reranking of the set $\{*$ Lapse, Parse- $\sigma$, AllFT-L/R \} captures the differences in metrification. Recall that in our earlier analysis of the initial underparsing effect in Cayuvava, an oppositeedge foot-alignment constraint (ALL-FT-Y) blocked the assignment of the initial foot, taking precedence over PARSE- $\sigma$ (see $(26 \mathrm{~b}, \mathrm{c})$ ). All it takes to derive the logically opposite effect of overparsing (or 'persistent footing') is the reversal of the ranking of these constraints:

(41) a. Non-persistent footing

$$
* \text { Lapse } \gg \text { All-Ft-X } \gg \text { All-Ft-Y } \gg \text { Parse- } \sigma
$$

b. Persistent footing

*LAPSE $\gg$ All-FT-X $\gg$ Parse- $\sigma \gg$ All-FT-Y

We have abstracted away from specific values $\mathrm{L}$ and $\mathrm{R}$ in foot alignment, capturing the wider generalisation for pairs of opposite-edge foot-alignment constraints.

Concretely, we can see the difference in ranking in the following comparison of relevant metrications in Cayuvava (where the opposite edge is R) and Chugach (where it is L):

(42) Parsing at 'opposite' edge in Cayuvava and Chugach

a. Cayuvava (non-persistent)

*LAPSE $\gg$ All-FT-L $\gg$ All-FT-R $\gg$ Parse- $\sigma$

i.ki.(tà.pa).re.(ré.pe).ha $\succ$ (í.ki).(tà.pa).re.(ré.pe).ha

b. Chugach (persistent)

$*$ LaPSE $\gg$ All-FT-R $\gg$ Parse- $\sigma \gg$ All-FT-L

(ma.yár).su.(qu.tá).(qu.ní) $\succ$ (ma.yár).su.(qu.tá).qu.ni

Let us now consider the full ranking that is required for the stress pattern of Chugach. The undominated status of *LAPSE should be evident from (37). But in fact we need a second undominated constraint:

(43) Align-L

Align (PrWd-L, Ft-L) 
Ternary rhythm and the lapse constraint 293

Without high-ranking ALIGN-L we would make incorrect predictions about the patterns of words of length $3 n+1$. Both of the candidates in (44) satisfy *LAPSE. However, (44b) is superior to (44a), the desired candidate, with respect to AlL-FT-R:

(44) Align-L $\gg$ All-Ft-R

(ma.yár).su.(qu.tá).(qu.ní) $\succ$ ma.(yar.sú).qu.(ta.qú).ni

It now appears that, once we have undominated *LAPse and Align-L, all ternarity effects can be attributed to ALL-FT-R. See the ranking in (45):

(45) Final ranking for Chugach

Align-L, *LAPSE $\gg$ All-FT-R $\gg$ Parse- $\sigma \gg$ All-Ft-L

Tableau (46) evaluates candidate metrifications of a seven-syllable form. The two-foot parse (46b) satisfies *LAPSE but fatally violates ALIGNL. (Generally, forms of $3 n+1$ syllables need minimally $n$ feet, to satisfy both Align-L and *Lapse. Hence, for a seven-syllable form, two feet at least are required.) Among the candidates that satisfy both ALIGN-L and *LAPSE, we identify a two-foot parse (46c) and various three-foot parses $(46 \mathrm{~d}-\mathrm{f})$. These are evaluated by AlL-FT-R, which excludes (46e, f), producing a tie between $(46 \mathrm{c}, \mathrm{d})$. These have identical parsings, except at the right margin, where the latter has a foot that the former lacks:

\begin{tabular}{|c|c|c|c|c|c|}
\hline /manarsuqutaquni/ & $\begin{array}{c}\text { AligN- } \\
\text { L }\end{array}$ & * LAPSE & $\begin{array}{c}\text { ALL-FT- } \\
\text { R }\end{array}$ & $\begin{array}{c}\text { PARSE- } \\
\sigma\end{array}$ & $\begin{array}{l}\text { AlL- } \\
\text { FT-L }\end{array}$ \\
\hline a. (ma.yár).su.qu.ta.qu.ni & & $*$ !** & ******* & ****** & \\
\hline b. ma.(yar.sú).qu.(ta.qú).ni & $* !$ & & * ***** & **** & ***** \\
\hline c. (ma.yár).su.(qu.tá).qu.ni & & & $* * * * * * *$ & $* *$ !* & **** \\
\hline$\leftrightarrow$ d. (ma.yár).su.(qu.tá).(qu.ní) & & & $* * * * * * *$ & * & $\begin{array}{c}* * * * \\
* * * * * *\end{array}$ \\
\hline e. (ma.yár).(su.qú).ta.(qu.ní) & & & $\begin{array}{c}* * * * \\
* * * * * * !\end{array}$ & * & $\begin{array}{c}\text { *** } \\
* * * * * *\end{array}$ \\
\hline f. (ma.yár).(su.qú).(ta.qú).ni & & & $\begin{array}{c}* * * * \\
* * * * * *\end{array}$ & * & $\begin{array}{c}* * * \\
* * * * *\end{array}$ \\
\hline
\end{tabular}

This tie is analogous to that seen in the evaluation of $3 n+2$ forms in Cayuvava, where it was resolved in favour of the form with the minimal number of feet, due to the activity of the opposite-edge foot-alignment constraint outranking syllable parsing (ALL-FT-R $\gg$ PARSE- $\sigma$ ). See again tableau $(26 \mathrm{~b}, \mathrm{c})$. But, in contrast to Cayuvava, Chugach is a persistentfooting system, in Hayesian terminology. In OT terms, this means that Chugach ranks Parse- $\sigma$ above All-FT-L (the opposite-edge foot-alignment constraint).

As already established in (44), Align-L must dominate All-FT-R in order for the three-foot parse (46d) to beat the suboptimal two-foot parse (46b). In sum, two ranking arguments are apparent from tableau (46): 
294 Nine Elenbaas and René Kager

(47) Ranking arguments

a. Align-L $\gg$ All-FT-R (ma.yár).su.(qu.tá).(qu.ní) $\succ$ ma.(yar.sú).qu.(ta.qú).ni

b. PARSE- $\sigma \gg$ All-Ft-L (ma.yár).su.(qu.tá).(qu.ní) $\succ$ (ma.yár).su.(qu.tá).qu.ni

Tableau (46) produces no direct evidence for the ranking ALL-FT-R $\gg$ PARSE- $\sigma$. Such evidence is forthcoming from a word of length $3 n$ syllables, as in tableau (48). The six-syllable form (48) is bound to a minimum of two feet, if it is not to violate any undominated constraint. (More generally, forms of $3 n$ syllables need minimally $n$ feet.) Three candidates survive undominated constraints: a pair of two-foot forms (48b, c) and an exhaustively parsed three-foot form (48f). ALL-FT-R selects (48c), since it has one fewer violation mark than its competitors $(48 \mathrm{~b}, \mathrm{f})$ :

\begin{tabular}{|c|c|c|c|c|c|}
\hline /akutartunirtuq/ & $\begin{array}{c}\text { Align- } \\
\text { L }\end{array}$ & LaPse & $\begin{array}{c}\text { All-FT- } \\
\mathrm{R}\end{array}$ & $\begin{array}{c}\text { PARse- } \\
\sigma\end{array}$ & $\begin{array}{c}\text { All- } \\
\text { FT-L }\end{array}$ \\
\hline a. (a.kú).tar.tu.nir.tuq & & $* ! *$ & $* * * *$ & $* * * *$ & \\
\hline b. (a.kú).(tar.tú).nir.tuq & & & $* * * * * * !$ & $* *$ & $* *$ \\
\hline c. (a.kú).tar.(tu.nír).tuq & & & $* * * * *$ & $* *$ & $* * *$ \\
\hline d. (a.kú).tar.tu.(nir.túq) & & $*$ ! & $* * * *$ & $* *$ & $* * * *$ \\
\hline e. a.(ku.tár).tu.(nir.túq) & $* !$ & & $* * *$ & $* *$ & $* * * * *$ \\
\hline f. (a.kú).(tar.tú).(nir.túq) & & & $* * * * * * !$ & & $* * * * * *$ \\
\hline
\end{tabular}

This tableau produces the desired argument for the ranking ALL-FT-R $\gg$ PARSE- $\sigma$.

(49) Ranking argument

AlL-FT-R $\gg$ PARSE- $\sigma$ (a.kú).tar.(tu.nír).tuq $\succ$ (a.kú).(tar.tú).(nir.túq)

In words of length $3 n+2$, two feet, spaced maximally apart, are correctly predicted to occur:

\begin{tabular}{|l|c:c|c|c|c|}
\hline$/$ taqamaluni/ & Align-L & $*$ LaPSE & All-FT-R & PARSE- $\sigma$ & AlL-FT-L \\
\hline a. (ta.qá).ma.lu.ni & & $* !$ & $* * *$ & $* * *$ & \\
\hline b. ta.(qa.má).lu.ni & $* !$ & & $* *$ & $* * *$ & $*$ \\
\hline c. (ta.qá).(ma.lú).ni & & & $* * * * !$ & $*$ & $* *$ \\
\hline d. (ta.qá).ma.(lu.ní) & & & $* * *$ & $*$ & $* * *$ \\
\hline
\end{tabular}

Finally, we must briefly address words with heavy syllables (containing a long vowel or a diphthong) presented in (51). ${ }^{11}$ Stress falls on every heavy syllable, and on every light syllable in position $3 n$ following a heavy

11 For space limitations, we will ignore the fact that initial closed syllables are treated as heavy. Page references are to Leer (1985). 
Ternary rhythm and the lapse constraint 295

syllable $(51 \mathrm{c}, \mathrm{d})$. In addition, light syllables in position $3 n-1$ following a heavy syllable are stressed if they are word-final (51b) or directly precede a heavy syllable (51e).

(51) a. (taá).(taá)

'her father' (L86)

b. (taá).(ta.qá)

'my father' (L86)

c. (naá).ma.(ci.qúq)

'it will suffice' (L84)

d. (naá).qu.(ma.lú).ku

e. (naá).(ma.cí).(quá)

'apparently reading it' (L89)

f. (mu.lú).(kuút)

'I will suffice' (L84)

g. (u.lú).te.(ku.tá).(raá) 'he’s going to watch her' (L104)

The key form is (51e), which shows that two light syllables in between heavies are footed, in order to avoid a lapse. Clearly, this lapse is not at the syllabic level, but at the MORAIC level, assuming that every mora projects a beat on the grid (Prince 1983, Kager 1993). Mora lapse occurs when a weak mora is not adjacent to either a strong mora or the word edge.

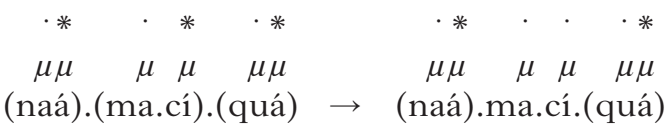

As indicated, long vowels and diphthongs in Chugach have rising mora prominence, with the second mora strong.

These quantity-sensitive patterns are accounted for by a simple extension of the grammar motivated for words with light syllables. We add undominated FTBIN- $\mu$ (Kager 1993, 1994) and WSP (Prince \& Smolensky 1993):

(53) a. FtBin- $\mu$

Feet are strictly bimoraic.

b. WSP

Heavy syllables are prominent within feet and on the grid.

Tableaux of a number of forms are presented below:

\begin{tabular}{|c|c|c|c|c|c|c|}
\hline a. /taataqa/ & $\begin{array}{c}\mathrm{FT}_{\mathrm{T}} \mathrm{B}_{\mathrm{IN}}- \\
\mu\end{array}$ & $\begin{array}{c}\text { AlIGN- } \\
\mathrm{L}\end{array}$ & *LAPSE & $\begin{array}{c}\text { ALL-FT } \\
\text { R }\end{array}$ & $\begin{array}{c}\text { PARSE- } \\
\sigma\end{array}$ & $\begin{array}{c}\text { ALL-FT- } \\
\text { L }\end{array}$ \\
\hline$\varpi$ (taá).(ta.qá) & & & & *** & & * \\
\hline (taá).ta.qa & & & & ** & $* ! *$ & \\
\hline \multicolumn{7}{|l|}{ b. /naamaciquq/ } \\
\hline (naá).(ma.cí).quq & & & & $* * * *$ ! & * & * \\
\hline (naá).ma.(ci.qúq) & & & & **** & * & ** \\
\hline \multicolumn{7}{|l|}{ c. /naamaciqua/ } \\
\hline (naá).ma.(ci.quá) & $* !$ & & $\mu$ & *** & * & ** \\
\hline (naá).ma.ci.(quá) & & & $\mu !$ & $* * *$ & ** & *** \\
\hline (naá).(ma.cí).(quá) & & & & $* * * *$ & & $* * * *$ \\
\hline
\end{tabular}




\section{Nine Elenbaas and René Kager}

This concludes the analysis of Chugach. Our main result in this section was an account of the difference between 'persistent' and 'non-persistent' ternarity, due to a simple reranking of two opposite-edge foot-alignment constraints (All-Ft-X, All-Ft-Y) with respect to Parse- $\sigma$. The next subsection briefly deals with an alternative analysis of Chugach, based on PARSE-2.

\subsection{An alternative: Parse-2}

Ishii (1996) proposes the following constraint ranking for Chugach:

(55) Align-L, Parse-2 $\gg$ All-Ft-R $\gg$ Parse- $\sigma$

Note that this analysis is minimally different from ours, the only difference being the use of PARSE-2 instead of *LAPSE. A tableau of the key seven-syllable form is presented below:

\begin{tabular}{|c|c|c|c|c|}
\hline /manarsuqutaquni/ & Align-L & PARSE-2 & All-FT-R & PARse- $\sigma$ \\
\hline a. (ma.yár).su.qu.ta.qu.ni & & $*$ ! $* * *$ & $* * * * *$ & $* * * * *$ \\
\hline b. (ma.yár).su.(qu.tá).qu.ni & & $*$ ! & $* * * * * * *$ & $* * *$ \\
\hline c. (ma.yár).su.(qu.tá).(qu.ní) & & & $* * * * * * *$ & $*$ \\
\hline d. (ma.yár).(su.qú).ta.(qu.ní) & & & $* * * * * * * * !$ & $*$ \\
\hline e. (ma.yár).(su.qú).(ta.qú).ni & & & $* * * * * * * *$ & $*$ \\
\hline
\end{tabular}

A question we must address is why this analysis works so smoothly, while the earlier attempt to analyse Cayuvava by PARSE- 2 was problematic. The difference resides in the fact that the Chugach pattern is persistent, whereas the Cayuvava pattern is non-persistent. The translation of 'persistent footing' into constraint format is achieved straightforwardly by Parse-2. That is, Alutiiq cannot serve to test the adequacy of *Lapse vs. PARSE-2, since both constraints are equally fit to analyse its pattern. Of course this leaves unaffected our earlier conclusion that such a translation was impossible in the case of Cayuvava, where the initial underparsing effect badly complicates the PARSE-2 analysis.

\section{Motivating *LAPSE}

Below we will further motivate the anti-lapse constraint * LAPSE on the basis of analyses of bounded non-ternary stress systems, arguing that it is not a ternarity-specific constraint. First, $\$ 4.1$ will demonstrate that * Lapse is empirically superior to Parse-2 in the analysis of Sentani, a language which has a bounded stress pattern in which ternary patterns occur. Its interest to the issue of the statement of the anti-lapse constraint is that it has feet of opposite dominance, allowing us to test our ' $r$ hythmic' theory against a 'parsing' theory of lapse. $\$ 4.2$ then reinforces the claim that *LAPSE is not a ternarity-specific constraint since it actually triggers rhythmic binarity in the analysis of Finnish stress. 


\subsection{The argument from Sentani: feet of opposite dominance}

Here we focus on an argument for grid-based *LAPSE from Sentani, a language that has feet of opposite dominance within a single word (Elenbaas 1999). But first we will set the stage for the argument by focusing on evaluation marks assigned by * LAPSE and PARSE-2, varying foot dominance within a word..$^{12}$ The following table displays all logically possible parses for which evaluations by *LAPSE and PARSE-2 differ:

\begin{tabular}{|c|c|c|c|c|}
\hline & two weak beats & * LAPSE & Parse-2 & \\
\hline Initial & 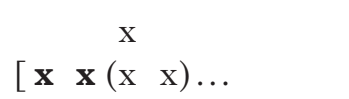 & $\checkmark$ & $*$ & Cayuvava \\
\hline Final & 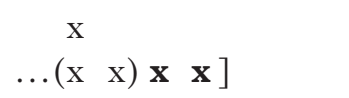 & $\checkmark$ & $*$ & $\begin{array}{l}\text { no examples } \\
\text { known }\end{array}$ \\
\hline Medial & 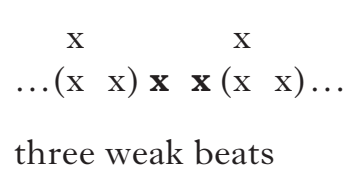 & $\checkmark$ & * & Sentani \\
\hline Medial & $\begin{array}{ccc}x & x \\
\ldots\left(\begin{array}{cc}x & x\end{array}\right) & x\left(\begin{array}{ll}x & x\end{array}\right) \ldots\end{array}$ & $*$ & $\checkmark$ & $\begin{array}{l}\text { no examples } \\
\text { known }\end{array}$ \\
\hline
\end{tabular}

Conflicting evaluations for * LAPSE and PARSE- 2 occurs in four contexts, two of which are not instantiated by languages currently known (hence there is no way of testing evaluations here). But in two cases we have empirical data from bearing on the correctness of evaluations. The case of stress on the third syllable (with the first two syllables left unparsed) is instantiated by initial underparsing in Cayuvava, for which we found * LAPSE to make the correct prediction. The other case is a local ternary rhythmic pattern, of two weak beats (on unparsed syllables) in between two strong beats (the first heading an iamb, the second a trochee). This parsing is predicted to be well-formed by *LAPSE, while PARSE- 2 rejects it. It is instantiated in Sentani, a finding which is of crucial importance to the issue of the proper statement of the anti-lapse constraint, and offering independent motivation for a rhythmic interpretation of *LAPSE. The actual argument from Sentani is complex, and it contains a number of steps.

Sentani is a Papuan language, spoken in Irian Jaya, the easternmost province of Indonesia (Elenbaas 1996, 1999). The rhythmic patterns of words of two to seven light syllables are exemplified below.

12 Earlier we presented patterns of evaluation marks for *LAPSE in (18) and PARSE-2 in (29), keeping foot dominance constant. 
298 Nine Elenbaas and René Kager

(58) a. bóhi
b. walóbo
c. fomàlére
d. haxòmibóxe 'forit'
e. molòkoxawále 'he obeyed them'
f. molòkoxàwaléne 'because I wrote to you'

Main stress always falls on the penult, with a secondary stress on the second syllable in words of minimally four syllables, and another secondary stress on the fourth syllable in words of seven or more syllables. The key comparison is between words of four and six syllables. Words of four syllables (58c) have stress on their second and third syllables, resulting in a clash. In contrast, words of six syllables (58e) are stressed on their second and fifth syllables. These lack secondary stress in clash with the main stress, resulting in a local ternary pattern.

Elenbaas argues that Sentani has an iambic stress system in which stress on final syllables is avoided. In (58c) we see that stress on the final syllable is avoided even at the cost of clash.

\begin{tabular}{|c|c|c|c|}
\hline /fomalere/ & Non-Fin & $\mathrm{FT}_{\mathrm{T}}=\mathrm{IAMB}$ & *CLASH \\
\hline 吼 a. (fo.mà).(lé.re) & & * & * \\
\hline b. (fò.ma).(lé.re) & & $* *$ ! & \\
\hline c. (fo.mà).(le.ré) & $* !$ & & \\
\hline
\end{tabular}

Sentani foot form is 'soft' in the sense that it is overruled by Non-Fin, but it is 'hard' in the sense that its enforcement may result in a clash. ${ }^{13}$ In sum, $\mathrm{FT}=\mathrm{IAMB}$ is minimally violated. (There is evidence that even the lowest-ranking constraint in the hierarchy, ${ }^{*} \mathrm{C}$ LASH, is active in Sentani. This will be argued for on the basis of words longer than four syllables.)

Let us now turn to the parsing of six-syllable forms. In (58e), the avoidance of final stress does not result in clash, but rather in a ternary rhythmic pattern. This means that, assuming strictly binary feet, two syllables remain unparsed. Consequently, we find that PARse- $\sigma$ is dominated by ${ }^{*} \mathrm{C}$ LASH (and by transitivity, all constraints mentioned earlier):

(60) Ranking argument

* Clash $\gg$ PARSE- $\sigma$ (mo.lò).ko.xa.(wá.le) $\succ$ (mo.lò).(ko.xà).(wá.le)

What evidence do we actually have for the crucial assumption that the metrification of a six-syllable word has an initial iamb and final trochee? Actually, the prediction from (60) is that the double-iambic lefthand form is optimal, rather than the mixed iambic-trochaic righthand form:

13 This clashing mixed iambic-trochaic pattern is found in other languages, such as Axininca Campa and Southern Paiute (Prince \& Smolensky 1993, Hung 1994). 
(61) Predicted parsing given current ranking (mo.lò).ko.(xa.wá).le $\succ$ (mo.lò).ko.xa.(wá.le)

But we can infer that the correct metrification is the (iambic-trochaic) righthand form in (61). This inference depends on two high-ranked wordto-foot-alignment constraints, Align-R and Align-L. We know that these constraints are high-ranked on the basis of shorter forms.

Without word-alignment constraints, and PARSE- $\sigma$ ranked so low in the hierarchy, we would expect a single-foot parsing of a four-syllable word to be selected as optimal:

(62) Align-L, Align-R $\gg$ FT $=$ Iamb (fo.mà).(lı́.re) $\succ$ fo.(ma.lé).re

That we find the two-foot parse indicates that words must begin and end in a foot. ${ }^{14}$

\begin{tabular}{|c|c|c|c|c|c|c|}
\hline /fomalere/ & Align-R & Align-L & $\begin{array}{l}\text { Non- } \\
\text { F IN }\end{array}$ & $\mathrm{F}_{\mathrm{T}}=\mathrm{I}_{\mathrm{AMB}}$ & * Clash & PARSE $-\sigma$ \\
\hline a. fo.(ma.lé).re & *! & * & & & & *** \\
\hline b. (fo.má).le.re & $* ! *$ & & & & & *** \\
\hline 咹 c. (fo.mà).(lé.re) & & & & * & * & \\
\hline d. (fo.mà).(le.ré) & & & $* !$ & & & \\
\hline
\end{tabular}

Assuming these high-ranked alignment constraints, we predict $(64 \mathrm{~b})$ as the optimal output in words consisting of six syllables.

\begin{tabular}{|c|c:c:c|c|c|c|}
\hline /molokoxawale/ & Allign- & Align- & Non- & FT $=$ & $*$ Clash & Parse- \\
& R & L & FIn & IAMB & & $\sigma$ \\
\hline a. (mo.lò).ko.(xa.wá).le & $* !$ & & & & & $* *$ \\
\hline mag b. (mo.lò).ko.xa.(wá.le) & & & & $*$ & & $* *$ \\
\hline c. (mo.lò).(ko.xà).(wa.lé) & & & $* !$ & & & \\
\hline d. (mo.lò).(ko.xà).(wá.le) & & & & $*$ & $*$ ! & \\
\hline e. (mo.lò).(kò.xa).(wá.le) & & & & $* * !$ & $*$ & \\
\hline f. (mò.lo).(kò.xa).(wá.le) & & & & $* * *$ & & \\
\hline
\end{tabular}

Now observe that the optimal form (64b) violates PARSE-2, although it satisfies *LAPSE. This completes the first step in the argument, to the effect that Sentani allows the mixed iambic-trochaic pattern with two unparsed syllables. But the argument is not complete yet. So far, we have not seen any evidence for the activity of an anti-lapse constraint of any kind, * Lapse nor Parse-2. All we know on the basis of the data seen so far is that

14 We have left Align-R and Align-L unranked with respect to each other. This simplifies the actual ranking, argued for by Elenbaas (1999), in which Align-R dominates Align-L. Also, we have omitted undominated FTBIN, which also dominates Align-L. (See three-syllable forms, for example (58b).) 


\section{Nine Elenbaas and René Kager}

if some anti-lapse constraint is active, it must be either *LAPSE, possibly undominated, or PARSE-2, positively dominated.

The evidence for an undominated grid-based anti-lapse constraint *LAPSE comes from the forms in (65). The seven-syllable forms in (65a) have three stresses (two secondaries plus a main stress), arranged in a perfect binary pattern.

(65) a. Seven syllables: perfect binarity

molòkoxàwaléne 'because I wrote to you'

ənàsəmòlonsánde 'they will go and bury me'

b. Seven syllables with schwa in $\sigma_{4}$ : stress shifts to next syllable, causing a clash

molònasəhàndéra 'after they will bury me'

əkàikeləwàimíle 'they went and taught them'

c. Six syllables with schwa in $\sigma_{3}$ : no stress shift or clash

alènnəxondére 'so that he gives a message with his feet'

jaxàrəmbondére 'for I will clarify'

The seven-syllable forms in (65b) differ from those in (65a) in their fourth syllables, which have schwa. As compared to the forms in (65a), secondary stress is now shifted to the fifth syllable, producing a clash with the primary stress. In contrast to the forms in $(65 \mathrm{a}, \mathrm{b})$, the six-syllable forms in (65c) lack the medial secondary stress.

Intuitively, schwa rejects stress, but stress is shifted to the following syllable (causing a clash) only if this helps avoiding a * LAPSE violation. To flesh out this intuition into constraint ranking, two independent issues should be addressed.

First, what licenses the medial secondary stress in the seven-syllable forms of $(65 b)$, which the six-syllable forms of $(65 c)$ lack? In the former case, the interval between the stresses on the second and penultimate syllable is three syllables. To avoid violation of *LAPSE, a stress is inserted either on the fourth (65a) or fifth syllable (65b). In the latter type, avoidance of lapse occurs at the expense of a clash:

(66) * LAPSE $\gg *$ CLASH

$$
\text { (mo.lò).na.(sə.hàn).(dé.ra) } \succ \text { (mo.lò).na.sə.han.(dé.ra) }
$$

In six-syllable forms the inter-stress interval is only two syllables. Hence, clash can be avoided without causing a fatal violation of lapse. This underparsing goes at the expense of violations of PARSE- $\sigma$, confirming a ranking already established for six-syllable forms (in tableau (64)):$$
\text { *Clash } \gg \text { Parse } \sigma
$$$$
\text { (a.lèn).nə.xon.(dé.re) } \succ \text { (a.lèn).(nə.xòn).(dé.re) }
$$

Second, what makes the secondary stress appear on the fifth syllable in $(65 \mathrm{~b})$, producing a clash, while secondary stress falls on the fourth 
Ternary rhythm and the lapse constraint 301

syllable in (65a)? It is the quality of the vowel in the fourth syllable that causes all the differences. Stress is prohibited from falling on schwa in an open syllable (Elenbaas 1999) $:{ }^{15}$

(68) *(C)á

No stressed schwa in open syllables.

Accordingly, we find:

(69) *(C)á 》 * CLASH (mo.lò).na.(sə.hàn).(dé.ra) $\succ$ (mo.lò).(na.sà).han.(dé.ra)

This gives the final ranking in $(70):{ }^{16}$

(70) Sentani : final ranking

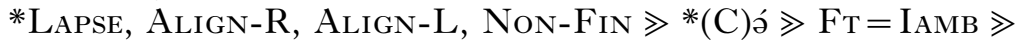

* Clash $\gg$ Parse $\sigma$

The following tableau shows the crucial interaction of *LAPSE, *(C)á, FT $=\mathrm{IAMB}$ and ${ }^{*} \mathrm{CLASH}$ :

\begin{tabular}{|c|c|c|c|c|c|}
\hline /molonasəhandera/ & *LAPSE & $*(\mathrm{C})$ & $\mathrm{F}_{\mathrm{T}}=\mathrm{I}_{\mathrm{AMI}}$ & * $\mathrm{CLASH}_{\mathrm{LSH}}$ & PARSE- $\sigma$ \\
\hline a. (mo.lò).na.(sə.hàn).(dé.ra) & & & * & * & * \\
\hline b. (mo.lò).(nà.sə).han.(dé.ra) & & & $* * !$ & * & * \\
\hline c. (mo.lò).(na.sà).han.(dé.ra) & & *! & * & & * \\
\hline d. (mo.lò).na.sə.han.(dé.ra) & *! & & * & & *** \\
\hline
\end{tabular}

We are now finally in a position to complete the argument that lapse avoidance in Sentani is grid-based rather than parsing-based. In tableau (71) we need an anti-lapse constraint to select (71a) instead of (71d). That this must be *LAPSE rather than PARSE- 2 becomes clear when we apply this ranking to a six-syllable form:

15 A constraint expressing the requirement that schwa be unstressed is proposed by Cohn \& McCarthy (1994): NonHEad-ə. This forbids stressing /ə/ altogether, regardless of whether its syllable is open or closed. However, this constraint does not capture the Sentani pattern, where closed syllables with /ə/ behave like other closed syllables. This situation cannot be reduced to an interaction between NonHead-ə and WSP; see Elenbaas (1999: 74).

16 The ranking $*(\mathrm{C}) a$ ’ $\gg \mathrm{FT}_{\mathrm{T}}=\mathrm{IAMB}$ is motivated by words like (àxə)(láne) 'in the forest'. Stress on the second syllable, which ends in a schwa, is avoided at the cost of a word-initial trochee. 


\begin{tabular}{|c|c|c|c|c|c|}
\hline /alennəxondere/ & *Lapse & *(C)á & $\mathrm{F}_{\mathrm{T}}=\mathrm{I}_{\mathrm{AMB}}$ & ${ }^{*} \mathrm{C}_{\text {LASH }}$ & Parse $-\sigma$ \\
\hline 雪 a. (a.lèn).nə.xon.(dé.re) & & & * & & *** \\
\hline b. (a.lèn).(nə.xòn).(dé.re) & & & * & $* !$ & \\
\hline
\end{tabular}

In contrast, when we use undominated PARSE-2, candidate (72a) is ruled out and the incorrect (72b) is selected. This analysis is unable to break the ranking paradox between PARSE- 2 and ${ }^{*}$ CLASH. (Words of six syllables lack clash, hence require $*$ CLASH $\gg$ PARSE- 2 , while the clash in words of seven syllables motivates Parse- $\gg * *^{*}$ Lash.) In sum, Sentani offers independent evidence for a rhythmic interpretation of the anti-lapse constraint.

Up to now we have presented arguments for a grid-based anti-lapse constraint on the basis of systematic ternarity (Cayuvava), and local ternary patterns in binary systems (Sentani). The key finding, on the basis of Sentani, is that *LAPSE is not a ternarity-specific constraint. That is, ternarity (of the 'systematic' Cayuvava/Chugach type) simply emerges from the interaction of constraints that are independently motivated for systems displaying 'occasional' ternarity. That is, systematic ternarity falls out from constraint interaction, a major result which we announced in the introduction.

Below we will reinforce the conclusion that * LAPSE is not a ternarityspecific constraint, demonstrating that it has a broad function of enforcing bounded (binary or ternary) patterns. It is even actively involved in selecting a binary pattern in Finnish.

\subsection{The argument from Finnish: *LAPSE enforcing binarity}

In Finnish (Carlson 1978, Kager 1992, Hanson \& Kiparsky 1996, Alber 1997, Elenbaas 1999) main stress falls on the word-initial syllable. Secondary stresses fall on every second syllable to the right $(73 \mathrm{a}-\mathrm{d})$ :
(73) a. măkä
b. périjä
'hill-NOM'
c. répeằmä
'inheritor-NOM'
d. érgonòmia
'crack, rupture-NOM'
e. púhelìmenàni
'ergonomics-NOM'
'telephone-Ess 1sG'
f. mátematìikka
'mathematics-NOM'
g. púhelimìstani
'telephones-ELAT 1sG'
h. rákastajàttariànsa 'mistresses-PART $1 \mathrm{sG}$ '

In $(73 \mathrm{f}-\mathrm{h})$ we observe deviations from binary alternation in the form of local ternary intervals. When the second syllable to the right of a preceding stress is light and the third is heavy (that is, closed or longvoweled), secondary stress shifts rightward onto the heavy syllable.

This mixed binary-ternary trochaic pattern can be predicted by the following ranking. The constraint named *(ĹH) (following Kager 1992, 
Ternary rhythm and the lapse constraint 303

Hanson \& Kiparsky 1996) militates against 'anti-trochees' composed of a light and a heavy syllable. ${ }^{17}$

(74) Align-L $\gg *(\dot{L} H) \gg$ PARSE- $\sigma \gg$ AlL-FT-L

Tableaux for selected examples in (73) are supplied below. Observe the left-oriented binary rhythm in $(75 a, b)$, where avoidance of LH trochees does not come into play. The three remaining tableaux show the lightsyllable-skipping effect due to avoidance of $\mathrm{LH}$ trochees. First, $(75 \mathrm{c})$, for a word with an odd number of syllables, produces the ranking argument for $*(\mathrm{LH}) \gg$ ALL-FT-L, while (75d, e), with an even number of syllables, demonstrate the ranking $*(\mathrm{LH}) \gg$ PARSE $-\sigma$. The avoidance of $\mathrm{LH}$ trochees now produces underparsing:

\begin{tabular}{|c|c|c|c|c|}
\hline a. /ergonomia/ & \begin{tabular}{|c|} 
ALIGN- \\
$\mathrm{L}$ \\
\end{tabular} & $*(\mathbf{L} H)$ & \begin{tabular}{|c|} 
PARSE- \\
$\sigma$ \\
\end{tabular} & ALL-FT-L \\
\hline 吼 (ér.go).(nò.mi).a & & & * & *** \\
\hline (ér.go).no.(mì.a) & & & * & $* * * !$ \\
\hline (ér.go).no.mi.a & & & *** !* & \\
\hline \multicolumn{5}{|l|}{ b. /puhelimenani/ } \\
\hline (pú.he).(lì.me).(nà.ni) & & & & *** **** \\
\hline (pú.he).li.(mè.na).ni & & & $* ! *$ & **** \\
\hline \multicolumn{5}{|l|}{ c. /matematiikka/ } \\
\hline (má.te).(mà.tiik).ka & & *! & * & 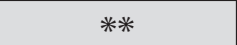 \\
\hline (má.te).ma.(tìik.ka) & & & * & **** \\
\hline \multicolumn{5}{|l|}{ d. /puhelimistani/ } \\
\hline (pú.he).(lì.mis).(tà.ni) & & $* !$ & & *** $* * * *$ \\
\hline (pú.he).li.(mìs.ta).ni & & & ** & **** \\
\hline \multicolumn{5}{|l|}{ e. /rakastajattariansa/ } \\
\hline (rá.kas).(tà.jat).(tà.ri).(àn.sa) & & ***! & & 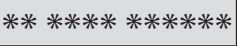 \\
\hline (rá.kas).(tà.jat).ta.(rì.an).sa & & ***! & ** & $* * * * * * *$ \\
\hline (rá.kas).ta.(jàt.ta).(rì.an).sa & & ***! & ** & **** $* * * * *$ \\
\hline 喁 (rá.kas).ta.(jàt.ta).ri.(àn.sa) & & * & ** & **** $* * * * * * *$ \\
\hline ra.(kás.ta).(jàt.ta).ri.(àn.sa) & *! & & ** & $* * * * * * * * * *$ \\
\hline
\end{tabular}

Next, observe that secondary stress on a final heavy syllable is always optional, regardless of whether it is odd-numbered $(76 \mathrm{a}, \mathrm{b})$ or evennumbered $(76 \mathrm{c}, \mathrm{d})$ in the parity count.

17 This slightly simplifies the actual ranking, which includes undominated constraints such as * Clash and FT $=$ TrocheE. See Elenbaas (1999) for details of the analysis of Finnish stress. 
304 Nine Elenbaas and René Kager

(76) a. kúningàs $\sim$ kúningas 'king-NOM'

b. káinostèlijàt $\sim$ káinostèlijat 'shy people-NOM'

c. rávintolàt $\sim$ rávintòlat 'restaurants-NOM'

d. mérkonomìn $\sim$ mérkonòmin 'degree in economics-GEN'

As we will see, a new argument for the anti-lapse constraint emerges from the pattern in $(76 \mathrm{c}, \mathrm{d})$.

The simplest case is that of words ending in LH and having an odd number of syllables. The dual patterns of $(76 \mathrm{a}, \mathrm{b})$ are obtained by leaving Non-FIn and PARSE- $\sigma$ unranked. When two interacting constraints are left unranked, each can dominate the other, giving two tableaux. The result is free variation (Anttila 1995, 1997). Leaving Non-FIN unranked with respect to PARSE- $\sigma$ gives both patterns for a word of five syllables, like kainostelijat.

(77) a.

\begin{tabular}{|c|c|c|c|c|c|}
\hline$/$ kainostelijat/ & Align-L & $*$ ĹH) & $\begin{array}{c}\text { Non- } \\
\text { F IN }\end{array}$ & PARse- $\sigma$ & AlL-FT-L \\
\hline i. (kái.nos).(tè.li).jat & & & & $*$ & $* *$ \\
\hline ii. (kái.nos).(tè.li).(jàt) & & & $* !$ & & $* * * * * *$ \\
\hline iii. (kái.nos).te.(lì.jat) & & $* !$ & & $*$ & $* * *$ \\
\hline iv. (kái.nos).te.li.jat & & & & $* * ! *$ & \\
\hline
\end{tabular}

b.

\begin{tabular}{|c|c|c|c|c|c|}
\hline /kainostelijat/ & Align-L & $*($ LH $)$ & PARSE- $\sigma$ & $\begin{array}{c}\text { Non- } \\
\text { FIn }\end{array}$ & AlL-FT-L \\
\hline i. (kái.nos).(tè.li).jat & & & $* !$ & & $* *$ \\
\hline ii. (kái.nos).(tè.li).(jàt) & & & & $*$ & $* * * * * *$ \\
\hline iii. (kái.nos).te.(lì.jat) & & $* !$ & $*$ & & $* * *$ \\
\hline iv. (kái.nos).te.li.jat & & & $* *$ ! & & \\
\hline
\end{tabular}

The ternary rhythmic parsing (77a.iii), (77b.iii), with a LH trochee, is correctly excluded regardless of ranking: its violation marks form a superset of those of the binary parsing (77a.i), (77b.i).

For words with an even-number of syllables $(76 \mathrm{c}, \mathrm{d})$, we find that NonFin must actually be able to rise high enough to dominate *(LH) so as to generate a binary pattern (rá.vin).(tò.lat). ${ }^{18}$ Surprisingly, however, this amendment does not suffice. A free ranking of NoN-FIN with respect to the opposite-edge constraint pair $*(\overline{\mathrm{L}} \mathrm{H}) \gg \mathrm{PARSE}-\sigma$ produces only two patterns, one with stress on the final syllable in (78a.i), and an ungrammatical single-foot parse in both (78b.iii) and (78c.iii).

18 Meanwhile *(ĹH) and PARSE- $\sigma$ must remain ranked as they are in the basic hierarchy in (74), in order to explain the obligatory underparsing in words like púhelimistani $(73 \mathrm{~g})$. 
Ternary rhythm and the lapse constraint 305

(78) a

\begin{tabular}{|r|c|c|c|c|c|}
\hline \multicolumn{1}{|c|}{ /ravintolat/ } & Align-L & $*$ (́́lH) & PARSE- $\sigma$ & Non-Fin & AlL-FT-L \\
\hline i. (rá.vin).to.(làt) & & $*$ & $*$ & $*$ & $* * *$ \\
\hline ii. (rá.vin).(tò.lat) & & $* * !$ & & & $* *$ \\
\hline iii. (rá.vin.).to.lat & & $*$ & $* * !$ & & \\
\hline
\end{tabular}

b.

\begin{tabular}{|c|c|c|c|c|c|}
\hline \multicolumn{1}{|c|}{ ravintolat/ } & Align-L & $*$ (́́L) & Non-Fin & PARSE- $\sigma$ & AlL-FT-L \\
\hline i. (rá.vin).to.(làt) & & $*$ & $* !$ & $*$ & $* * *$ \\
\hline ii. (rá.vin).(tò.lat) & & $* * !$ & & & $* *$ \\
\hline iii. (rá.vin.).to.lat & & $*$ & & $* *$ & \\
\hline
\end{tabular}

c.

\begin{tabular}{|c|c|c|c|c|c|}
\hline \multicolumn{1}{|c|}{ ravintolat/ } & ALIGN-L & NoN-FIN & $*$ (Ĺ) & PARSE- $\sigma$ & ALL-FT-L \\
\hline i. (rá.vin).to.(làt) & & $* !$ & $*$ & $*$ & $* * *$ \\
\hline ii. (rá.vin).(tò.lat) & & & $* * !$ & & $* *$ \\
\hline iii. (rá.vin.).to.lat & & & $*$ & $* *$ & \\
\hline
\end{tabular}

d.

\begin{tabular}{|c|c|c|c|c|c|c|}
\hline /ravintolat/ & Align-L & * LAPSE & $\begin{array}{c}\text { Non- } \\
\text { FIN }\end{array}$ & *(ílH) & $\begin{array}{c}\text { Parse- } \\
\sigma\end{array}$ & ALL-FT-L \\
\hline i. (rá.vin).to.(làt) & & & $* !$ & * & * & *** \\
\hline 世 ii. (rá.vin).(tò.lat) & & & & *** & & *** \\
\hline iii. (rá.vin.).to.lat & & *! & & * & ** & \\
\hline
\end{tabular}

To absolutely rule out the single-foot candidate, and to force the binary candidate prominently into the output set, an undominated anti-lapse constraint must be involved. This we assume to be *LAPSE, here involved in selecting a binary pattern. As shown in (78d), the surprising result is that *LAPSE, motivated in earlier sections on the basis of ternary stress systems, now functions to force rhythmic binarity.

In this and the previous section we have seen how an anti-lapse constraint licenses ternary patterns in otherwise non-ternary systems like Sentani and Finnish. For the latter language, we also saw *LApse license a binary pattern, while rejecting quaternary patterns. In sum, *LAPSE licenses rhythmic BoundeDNESs, either binarity or ternarity. Crucially, unlike Weak Local Parsing in serial theory, or its OT counterpart, the foot-repulsion constraint * FTFT, *LAPSE does not enforce ternarity. As already argued at the end of the previous section on Sentani, a highly desirable conclusion follows from this - we now have a unified treatment of ternarity, which generalises to both systematic ternarity (Cayuvava, Chugach) and 'fleeting' ternarity (Sentani, Finnish).

In accordance with the OT programme of reducing typological variation to reranking of a set of universal constraints, we are now able to accommodate the bounded stress systems within a cohesive factorial typology, simply by reranking * LAPSE and other constraints. Whereas all existing theories, including ours, require some kind of mechanism to handle ternarity (ternary feet, Weak Local Parsing, a foot-repulsion 


\section{Nine Elenbaas and René Kager}

constraint or an anti-lapse constraint), the special virtue of our lapsebased theory is that it produces a very tight factorial typology.

This sets the stage for the final step in the argument: showing that a reranking of *LAPSE produces an adequate factorial typology. In earlier sections we already saw certain typological results emerge. First, the typological distinction between ternary systems and binary systems. In binary systems (like Pintupi and Finnish) the ranking is * LAPSE, PARSE- $\sigma$ $\gg$ AlL-FT-X, while in ternary systems (like Cayuvava and Chugach) we find a ranking *LAPSE $\gg$ ALL-FT-X $\gg$ PARSE- $\sigma$. This is the core typological result, residing in the reranking of PARSE- $\sigma$ and ALL-FT-X. We also argued that the difference between persistent and non-persistent ternarity resides in reranking of PARSE- $\sigma$ with respect to the opposite-edge footalignment constraint ALL-FT-Y. In $\$ 5$ a more complete factorial typology will be presented.

\section{Factorial typology}

One particularly useful way of addressing the issue of the proper antilapse constraint is the construction of factorial typologies. If we compare these factorial typologies on the criterion of how closely they match actually attested stress systems, we may find reasons to prefer one set of constraints over the other.

A factorial typology arises from the permutation of a set of constraints. This is a task of considerable analytic complexity, give the number of logically possible rankings. With six constraints, the number of rankings is 6 ! (720), with seven constraints, 7 ! (5040), etc. Fortunately the actual number of generated patterns is far smaller, due to the fact that formally distinct rankings often produce identical patterns. For example, in the factorial typology of * LAPSE we have used six constraints, producing 720 different rankings, but only fifteen distinct patterns, a reduction of almost $98 \%$.

Nevertheless, to decrease the complexity of the comparison of models, we have chosen to consider only constraints of crucial relevance to rhythmic spacing. In our rhythmic theory of ternarity, this set includes the anti-lapse constraint (*LAPSE), the constraint enforcing metrical parsing (PARSE- $\sigma$ ), and constraints evaluating distances of feet with respect to one another, or to domain edges. In the latter category we find two types of alignment constraint, Align-X and All-FT-X, where $\mathrm{X}$ is an edge, left or right. Establishing the factorial typology of this set of six constraints turned out to be a considerable task. Due to lack of space, we have been unable to include in the typology any constraints governing quantity-sensitivity, foot-headedness or the distinction of main vs. secondary stress. Nor have we considered any rankings in which FTBIN (Prince 1980, Prince \& Smolensky 1993) is dominated. ${ }^{19}$

19 A proposal for patterns with degenerate feet is made by Green \& Kenstowicz (1995). See also Kiparsky (1991), Hayes (1995) and Kager (1995) for theories of degenerate feet. 
Ternary rhythm and the lapse constraint 307

So our necessarily restricted goal is to develop a factorial typology of quantity-insensitive styles of alternation, assuming the RHYTHMIC THEORY of ternarity, with the constraints in (79):

\section{*Lapse, Align-X/Y, All-Ft-X/Y, Parse- $\sigma$}

After having constructed the typology of this set in $\S \S 5.1-4$, we turn to comparison with alternative theories.

An adequate typology should contain all empirically attested stress systems, while ideally it should not contain more than these. However, $a$ priori we cannot expect a $100 \%$ match between the predicted factorial typology and the stress systems of natural languages, as we will have to allow for accidental gaps. Consequently, we will evaluate the adequacy of the factorial typology by focusing on predictions about classes of patterns that are systematically absent in stress languages.

We will argue that in terms of the ALL-AND-ONLY criterion, rhythmic theory generates all of the attested ternary systems, while its overgeneration is within reasonable limits. In terms of restrictiveness, rhythmic theory is superior to any of its competitors. In $\$ 5.5$ we discuss PARSING THEORY, based on the anti-lapse constraint PARSE- 2 and the foot-repulsion constraint *FTFT (which is necessary to generate the Cayuvava pattern). Parsing theory overgenerates severely by predicting patterns of a nondirectional nature, where the distribution of alternating stresses is not oriented toward a unique edge of the word. Such stress patterns are completely unattested in languages currently known. Finally, in $\$ 5.6$ we will briefly compare the typology of OT-based rhythmic theory with that of rule theory (assuming the Hayesian parameters of Weak Local Parsing and persistent footing).

\subsection{A basic factorial typology of * LAPSE}

Here we will construct the factorial typology of rhythmic theory, using the grid-based *LAPSE. Temporarily ignoring effects of word-to-foot alignment (Align-X), we first consider the basic typology, resulting from the reranking of three constraints (*Lapse, All-Ft-X, Parse- $\sigma$ ). These constraints allow for six (i.e. 3 !) logically possible rankings, laid out below.

(80) a. All-Ft-X $\gg$ Parse $-\sigma \gg *$ Lapse (unbounded systems)

b. All-Ft-X $\gg *$ LAPSE $\gg$ PARSE- $\sigma \quad(=80 \mathrm{a})$

c. PARSE $-\sigma \gg *$ LaPSE $\gg$ All-FT-X (binary rhythm)

d. Parse- $\sigma \gg$ All-FT-X $\gg *$ Lapse $\quad(=80 \mathrm{c})$

e. $*$ LAPSE $\gg$ PARSE $-\sigma \gg$ All-Ft-X $\quad(=80 \mathrm{c})$

f. *Lapse $\gg$ All-Ft $-\mathrm{X} \gg$ Parse- $\sigma$ (ternary rhythm)

The six logically possible rankings produce only three distinct patterns. 


\section{Nine Elenbaas and René Kager}

The rankings $(80 \mathrm{a}, \mathrm{b})$ both result in unbounded stress systems, with a single foot fixed at edge $\mathrm{X}$ of the word, where $\mathrm{X}$ is $\mathrm{L}$ or R, as in (81a).

(81) a.

\begin{tabular}{|c|c|c|c|}
\hline & ALL-FT-L & PARSE- $\sigma$ & *LAPSE \\
\hline$\notin(\dot{\sigma} \sigma) \sigma \sigma \sigma \sigma \sigma \sigma$ & & $* * * * * * *$ & $* * * * *$ \\
\hline$(\dot{\sigma} \sigma) \sigma(\dot{\sigma} \sigma) \sigma(\dot{\sigma} \sigma)$ & $* ! * * * * * * * *$ & $* *$ & \\
\hline$(\dot{\sigma} \sigma)(\dot{\sigma} \sigma)(\dot{\sigma} \sigma)(\dot{\sigma} \sigma)$ & $* ! * * * * * * * * * * *$ & & \\
\hline
\end{tabular}

b.

\begin{tabular}{|c|c|c|c|}
\hline & PARSE- $\sigma$ & ALL-FT-L & *LAPSE \\
\hline$(\sigma \sigma \sigma) \sigma \sigma \sigma \sigma \sigma \sigma$ & *! $* * * * *$ & & ****** \\
\hline$(\dot{\sigma} \sigma) \sigma(\dot{\sigma} \sigma) \sigma(\dot{\sigma} \sigma)$ & $* ! *$ & $* * * * * * * * *$ & \\
\hline$\bigoplus(\dot{\sigma} \sigma)(\dot{\sigma} \sigma)(\dot{\sigma} \sigma)(\dot{\sigma} \sigma)$ & & ***************** & \\
\hline
\end{tabular}

c.

\begin{tabular}{|c|c|c|c|}
\hline & $*$ LAPSE & ALL-FT-L & PARSE- $\sigma$ \\
\hline$(\dot{\sigma} \sigma) \sigma \sigma \sigma \sigma \sigma \sigma$ & $* ! * * * *$ & & $* * * * * *$ \\
\hline$Æ(\dot{\sigma} \sigma) \sigma(\dot{\sigma} \sigma) \sigma(\dot{\sigma} \sigma)$ & & $* * * * * * * * *$ & $* * *$ \\
\hline$(\dot{\sigma} \sigma)(\dot{\sigma} \sigma)(\dot{\sigma} \sigma)(\dot{\sigma} \sigma)$ & & $* * * * * * * * * * * * *$ & \\
\hline
\end{tabular}

The rankings of $(80 \mathrm{c}, \mathrm{d})$, on the other hand, require the word to be exhaustively parsed, which results in the strictly binary systems in (81b). The same result is obtained when ALL-FT-L is outranked by both PARSE$\sigma$ and $*$ LAPSE as in (80e). Finally, (80f) is the ranking discussed in $\$ 3$ (Cayuvava) and $\S 4$ (Chugach), resulting in ternary rhythm. Here *LAPSE is undominated, with ALL-FT-X (the underparsing constraint) dominating PARSE- $\sigma$, as in (81c). In sum, we find three major rankings, representing unbounded, binary and ternary systems:

(82) Rhythmic theory : the basic typology
a. All-FT-X $\gg$ Parse- $\sigma$, *LAPSE
(unbounded systems)
b. *Lapse, Parse $\sigma \gg$ All-FT-X
(binary systems)
c. * Lapse $\gg$ All-Ft $-\mathrm{X} \gg$ Parse- $\sigma$
(ternary systems)

Below we will expand this basic rhythmic typology by introducing additional factors, such as ALIGN-X (producing edge effects), and varying the values of X in ALL-FT-X. Our focus will be on ternary systems ( $\$ 5.4)$, but we first lay out the typologies of unbounded systems $(\$ 5.2)$ and strictly binary systems $(\$ 5.3)$.

At this point we must address the role of foot dominance. Since *LAPSE measures beats on the grid (rather than the parsing of weak syllables by feet), foot dominance matters to the evaluation by *LAPSE, and it also interacts with the edges $(\mathrm{X} / \mathrm{Y})$ specified in alignment constraints. This means that every pattern derived below comes in two variants, one trochaic and another iambic, complete mirror images of one another. Only 
Ternary rhythm and the lapse constraint 309 one of these patterns will be discussed, except when both are empirically attested.

\subsection{Unbounded systems}

As seen above, unbounded systems arise when ALL-FT-X is undominated, for only one foot in a word can be strictly adjacent to edge $\mathrm{X}$. This singleedged unbounded pattern can be locally modified into a double-edged 'hammock' pattern by ranking ALIGN-Y above AlL-FT-X:

(83) Unbounded systems
a. All-Ft-X $\gg$ Parse $\sigma$, * Lapse
(one foot at edge $\mathrm{X}$ )
b. Align-Y $\gg$ All-Ft-X $\gg$ PARSE- $\sigma$, (hammock pattern, feet at *LAPSE both edges)

Hammock patterns have both edges marked by stresses, while medial stresses are absent. The 'initial+ penult' pattern is attested in GuguYalanji (Oates \& Oates 1964), its mirror image 'penult + initial' pattern in Sibutu Sama (Allison 1979, Kager 1997), exemplified below.

(84)
Sibutu Sama: Align-R $\gg$ All-Ft-L $\gg$ Parse- $\sigma$, *LAPSE
a. bis.(sá.la) 'talk'
b. (bìs.sa).(lá.han) 'persuading'
c. (bìs.sa).la.(hán.na) 'he is persuading'
d. (bìs.sa).la.han.(ká.mi) 'we are persuading'

The tableau for a six-syllable Sibutu Sama form is given below:

\begin{tabular}{|c|c|c|c:c|}
\hline /bissalahankami/ & ALIGN-R & ALL-FT-L & PARSE- $\sigma$ & $*$ LAPSE \\
\hline a. (bìs.sa).(là.han).(ká.mi) & & $* * * * * ! *$ & & \\
\hline b. (bís.sa).la.han.ka.mi & $* !$ & & $* * * *$ & $* * *$ \\
\hline c. (bìs.sa).la.han.(ká.mi) & & $* * * *$ & $* *$ & $*$ \\
\hline d. bis.sa.la.han.(ká.mi) & & $* * * *$ & $* * * ! *$ & $* *$ \\
\hline
\end{tabular}

\subsection{Binary rhythmic systems}

As discussed in $§ 1.1$, binary rhythmic systems arise when we keep FTBIN undominated, with PARSE- $\sigma$ outranking ALL-FT-X. Footing is exhaustive, except that words with an odd number of syllables have a residual unparsed syllable, which cannot be footed by binary feet. High-ranked PARSE- $\sigma$ automatically precludes lapses (allowing us to assume un- 
310 Nine Elenbaas and René Kager

dominated *LAPSE in rankings below). No lapses arise, as the unparsed syllable can, logically speaking, only occupy two positions, both of which are 'rhythmically licensed' by *LAPSE: at an edge or adjacent to a foot head.

\section{(86) A single unparsed syllable necessarily satisfies * LAPSE}
a. unparsed syllable at edge
$\left(\sigma^{\prime} \sigma\right)(\dot{\sigma} \sigma)(\sigma \dot{\sigma}) \sigma$
b. unparsed syllable adjacent to head of foot
$(\sigma \dot{\sigma} \sigma)(\dot{\sigma} \sigma) \sigma(\dot{\sigma} \sigma)$

The typology of binary systems arises by reranking ALL-FT-X with respect to PrWd-to-Ft-alignment constraints (ALIGN-X). In rankings, undominated FTBIN and *LAPSE are suppressed from now on:

(87) Iterative binary systems
a. PARSE- $\sigma \gg$ All-FT-X unidirectional
b. Align-X, Parse- $\sigma \gg$ All-Ft-Y bidirectional (simple)
c. Align-X, Parse- $\sigma \gg$ Align-Y $\gg$ All-Ft-X bidirectional (complex)
(Indonesian)
(Pintupi/Warao)
(Piro/Garawa)

The unidirectional type (87a) is exemplified by Pintupi ( $\$ 1.2)$, which has stress on the initial syllable and on following alternating syllables. Feet are oriented toward the left edge by ALL-FT-L. Here we exemplify its mirror image, with foot alignment towards the right edge, as in Warao (Osborn 1966), which stresses the penult and preceding alternating syllables.

a. ko.(rá.nu)

'drink it!'

b. yi.(wà.ra).(ná.e)

'he finished it'

c. (yà.pu).(rù.ki).(tà.ne).(há.se)

d. e.(nà.ho).(rò.a).(hà.ku).(tá.i)

'verily to climb'

'the one who caused him to eat'

Note that in unidirectional systems the unparsed syllable is consistently at the same edge.

Bidirectional systems differ from unidirectional systems by fixing one foot at an edge, and constructing iterative feet from the opposite edge. For example, Piro (Matteson 1965) stresses the penult, plus the initial and alternate syllables following it. In words of an odd number of syllables, the unparsed syllable directly precedes the final foot:

(89) Piro: Align-R, Parse- $\sigma \gg$ All-Ft-L
a. ru.(txí.txa)
'he observes taboo'
b. (sà.lwa).ye(hká.kna)
'they visit each other'
c. (pè.tfi).(tghì.ma).(tló.na) 'they say they stalk it'
d. (rù.slu).(nò.ti).ni.(tká.na) 'their voices already changed' 
Ternary rhythm and the lapse constraint 311

Bidirectional systems arise by promotion of ALIGN-X above ALL-FT-Y. A tableau of a seven-syllable word of Piro illustrates this:

\begin{tabular}{|r|c:c|c|}
\hline /ruslunotinitkana/ & Align-R & PARSE- $\sigma$ & AlL-FT-L \\
\hline a. (rù.slu).(nò.ti).(ní.tka).na & $* !$ & $*$ & $* * * * * *$ \\
\hline b. (rù.slu).(nò.ti).ni.(tká.na) & & $*$ & $* * * * * * *$ \\
\hline c. (rù.slu).no.(tì.ni).(tká.na) & & $*$ & $* * * * * * * * !$ \\
\hline d. ru.(slù.no).(tì.ni).(tká.na) & & $*$ & $* * * * * * * * * *$ \\
\hline e. ru.slu.no.ti.ni.(tká.na) & & $* * ! * * *$ & $* * * * *$ \\
\hline
\end{tabular}

Its mirror image is Garawa (Furby 1974, McCarthy \& Prince 1993b), where stress is on the initial syllable, and on alternating syllables preceding the penult. Feet are oriented toward the right edge, due to ALLFT-R:

(91) Garawa: Align-L, Parse- $\sigma \gg$ All-Ft-R
a. (pún.ja).la
'white'
b. (ká.ma).la.(rí.ni)
'wrist'
c. (yá.ka).(là.ka).(là.mpa)
'loose'
d. (yán.ki).ri.(kì.rim).(pà.yi) 'fought with boomerangs'

Yet another contribution of ALIGN-X to the factorial typology resides in the generation of what we will refer to as 'complex bidirectional' patterns. These are patterns in which stress is fixed at both edges, with rhythmic stresses in between. ${ }^{20}$ Probably the best-known example of such a system is Indonesian (Cohn 1989), where main stress is on the penult and a secondary stress on the initial syllable in words of minimally four syllables long. In words of six or more syllables, there is a leftward alternation of secondaries on syllables preceding the penult:

(92) Indonesian: Align-R, Parse- $\sigma \gg$ Align-L $\gg$ All-Ft-R
a. bi.(cá.ra)
'speak'
b. (kòn.ti).nu.(á.si)
'continuation'
c. (è.ro).(dì.na).(mí.ka) 'aerodynamics'
d. (à.me).ri.(kà.ni).(sá.si) 'Americanisation'

Note that any differences between the patterns of Indonesian and Piro can

20 This is attested in Sentani, although high-ranked * CLASH obscures any visible effects of directionality. 
312 Nine Elenbaas and René Kager

only be inferred from words of (minimally) seven syllables, which makes the contrast rather subtle.

\begin{tabular}{|c|c|c|c|c|}
\hline /amerikanisasi/ & ALIGN-R & PARSE- $\sigma$ & ALIGN-L & ALL-FT-R \\
\hline a. (à.me).(rì.ka).(ní.sa).si & $* !$ & $*$ & & $* * * * * * * * *$ \\
\hline b. (à.me).(rì.ka).ni.(sá.si) & & $*$ & & $* * * * * * * * !$ \\
\hline c. (à.me).ri.(kà.ni).(sá.si) & & $*$ & & $* * * * * * *$ \\
\hline d. a.(mè.ri).(kà.ni).(sá.si) & & $*$ & $* !$ & $* * * * * *$ \\
\hline e. (à.me).ri.ka.ni.(sá.si) & & $* * ! *$ & & $* * * * *$ \\
\hline
\end{tabular}

In sum, the factorial typology of binary rhythm is fully adequate as judged by the all-and-only criterion: it coincides with the range of empirically attested quantity-insensitive patterns.

\subsection{Ternary rhythmic systems}

The core ranking of ternary systems, established in $\S 2$, is repeated below :

$*$ Lapse $\gg$ All-Ft $-\mathrm{X} \gg$ Parse $-\sigma$

Align-X can be inserted into this ranking in different positions, with the additional option of varying the value of $\mathrm{X}$ in ALL-FT-X. The typology then branches out into five subtypes:

(95) Iterative ternary systems

a. ${ }^{*}$ LaPSE $\gg$ AlL-FT-X $\gg$ Parse $-\sigma$ unidirectional (loosely aligned)

b. Align-X, *Lapse $\gg$ All-Ft-Y $\gg$ Parse- $\sigma$ unidirectional (strictly aligned)

(Cayuvava/Winnebago)

c. Align-X, *Lapse $\gg$ All-Ft-X $\gg$ Parse- $\sigma$ bidirectional (simple, loosely aligned)

d. Align-X $*$ Lapse $\gg$ Align-Y $\gg$ All-Ft-X $\gg$ Parse- $\sigma$ bidirectional (simple, strictly aligned)

e. Align-X, *Lapse $\gg$ Align-Y $\gg$ All-Ft-Y $\gg$ Parse- $\sigma$ bidirectional (complex)

Each of these subtypes will be discussed below, and exemplified whenever possible.

5.4.1 Unidirectional systems: loosely aligned. The first branch of the ternary family is unidirectional, with 'loose' alignment of feet at edge X, 
Ternary rhythm and the lapse constraint 313

from which alternation starts. By 'loose' alignment we mean that footing does not start by strictly aligning the first foot at edge $\mathrm{X}$, but by skipping (one or two) syllables at that edge.

The clearest member of this family is Cayuvava, where a trochee is loosely aligned at the right edge. As we saw in $\$ 3$, loose alignment does not require Non-FIN, but simply results from trochees being pulled maximally leftward while respecting the maximal sequence of weak beats, captured by the ranking *LAPSE $\gg$ ALL-FT-L $\gg$ PARSE- $\sigma$. We also saw that a second defining characteristic of Cayuvava, its initial underparsing ('double upbeat') in words of length $3 n+2$ syllables, arises from the ranking All-FT-R $\gg$ PARSE- $\sigma$ :

\begin{tabular}{|c|c|c|c|c|}
\hline /ikitaparerepeha/ & *LAPSE & ALL-FT-L & ALL-FT-R & PARSE- $\sigma$ \\
\hline a. (ì.ki).(tà.pa).(rè.re).(pé.ha) & & $\begin{array}{l}* * * * * * \\
* * ! * * * *\end{array}$ & $\begin{array}{l}* * * * * * \\
* * * * * *\end{array}$ & \\
\hline b. (ì.ki).(tà.pa).re.(ré.pe).ha & & ******** & $\begin{array}{c}* * * * * * \\
* ! * * * * * * \\
\end{array}$ & *** \\
\hline c. i.ki.(tà.pa).re.(ré.pe).ha & & ********* & ****** & ***** \\
\hline
\end{tabular}

As can be seen in this tableau, a minimal variation on this pattern is predicted by a promotion of PARSE- $\sigma$ above AlL-FT-Y, producing a persistent ternarity effect. Then candidate (96b) with an initial foot would be selected, rather than the double-upbeat candidate (96c).

This predicted pattern is perhaps attested, albeit with a reversal of both directionality and foot dominance as compared to Cayuvava. A language which displays this persistent ternarity effect is Winnebago. Miner (1979: 28) gives the following rule of accentuation: 'accent every third mora as long as three are available; otherwise, accent a second mora'. Moras (rather than syllables) are stress units, as is shown by the behaviour of long vowels in the first syllable of a word, which are split between feet, for example in (97f) (references to Miner 1979, unless otherwise stated).
a. (was.gé)
b. ho.(ta.xí)
c. hi.(dzo.wí).re
d. ho.(ki.wá).(ro.ké)
e. ho.(ki.wá).ro.(ro.ké) 'swing (v INTR)' (Miner 1981: 342)
f. hi(i.zú).go.(ki.rús).ge 'double-barrelled shotgun’ (M28)

Assuming the correctness of this description (but see the discussion below), Winnebago appears to be an iambic ternary system with initial extrametricality. As argued earlier, extrametrically is not a primitive in the analysis of 'loose alignment', but falls out from the interaction of the antilapse constraint and foot alignment. This is simply the mirror image of Cayuvava. That is, the 'third mora' effect derives from *LAPSE (limiting 


\section{Nine Elenbaas and René Kager}

the distance between the leftmost stress and word edge to two moras) ranked above ALL-FT-R (pulling feet maximally to the right). If this is correct, then Winnebago instantiates the predicted 'persistent' counterpart of the Cayuvava pattern. Persistence (which, of course, is visible only in words of $3 n+2$ syllables) is due to the ranking of PARSE- $\sigma$ above AlLFT-L (98a). All other Winnebago words (of $3 n$ or $3 n+1$ syllables) behave analogously to words of similar lengths in Cayuvava. Stress falls on every third mora counting from the edge.

\begin{tabular}{|c|c|c|c|c|}
\hline /hokiwaroke/ & *LAPSE & ALL-FT-R & PARSE- $\sigma$ & ALL-FT-L \\
\hline ho.(ki.wá).(ro.ké) & & ** & * & ***** \\
\hline (ho.kí).wa.(ro.ké) & & ***! & * & *** \\
\hline (ho.kí).(wa.ró).ke & & $* * * ! *$ & * & ** \\
\hline ho.(ki.wá).ro.ke & & ** & *** ! * & * \\
\hline ho.ki.(wa.ró).ke & $* !$ & * & & ** \\
\hline \multicolumn{5}{|l|}{ b. /hokiwaroroke/ } \\
\hline (ho.kí).(wa.ró).(roké) & & ******** & & ******* \\
\hline (ho.kí).wa.(ro.ró).ke & & ******* & ** & **** \\
\hline ho.(ki.wá).ro.(ro.ké) & & **** & ** & $* * * * *$ \\
\hline ho.(ki.wá).(ro.ró).ke & & $* * * * !$ & ** & ***** \\
\hline ho.ki.(wa.ró).ro.ke & $* !$ & & ***** & *** \\
\hline \multicolumn{5}{|l|}{ c. /hiizugokirusge/ } \\
\hline hi(i.zú).(go.kí).(rus.gé) & & $* * * * * * !$ & * & ********** \\
\hline hi(i.zú).go.(ki.rús).ge & & * ***** & **** & * ***** \\
\hline hi(i.zú).(go.kí).rus.ge & & $* * * * * * *$ & **** & * *** \\
\hline (hií).zu.(go.kí).rus.ge & & ******* & **** & $* * *$ \\
\hline hii.zu.(go.kí).rus.ge & $* ! *$ & *** & ****** & **** \\
\hline
\end{tabular}

However, Winnebago's ternary rhythm is controversial. Hale \& White Eagle (1980), and in their footsteps Halle \& Vergnaud (1987) and Halle (1990), argue that rhythmic alternation rightward from the third mora is binary. Hayes (1995), reviewing the primary literature on the language (including Susman 1943 and Miner 1989), arrives at the conclusion that Winnebago has both binary and ternary patterns, and that the factors governing their distribution are still unclear. Hayes also questions the actual foot distribution assumed in earlier literature, arguing for strict alignment at the left edge, in combination with an autosegmental reassociation rule shifting a high tone to the immediately following syllable. With so many discrepancies in the literature with respect to rhythmic pattern and analysis, it is too early to claim Winnebago as a clear-cut instantiation of a persistent ternarity system.

Returning to the typology, we have now seen two members of the family of unidirectional 'loosely aligned' ternary systems: a 'non-persistent' 
Ternary rhythm and the lapse constraint 315

pattern (Cayuvava) and its 'persistent' counterpart (hypothetical Winnebago). In both systems, stress is fixed on the third syllable from the 'starting edge', with a single unparsed syllable separating the foot from this edge. A generalisation holds for these systems: foot dominance is opposite to the starting edge. For example, in Cayuvava the starting edge is $\mathrm{R}$, opposite to the left-dominant foot (trochee).

But there is yet another predicted member of this family of loosely aligned patterns, which minimally differs from the ones discussed earlier in having two unparsed syllables at the edge where alternation starts. This pattern occurs when foot dominance matches the starting edge. For example, antepenultimate stress may be achieved by a R-dominant foot separated by two unparsed syllables from the starting edge R.

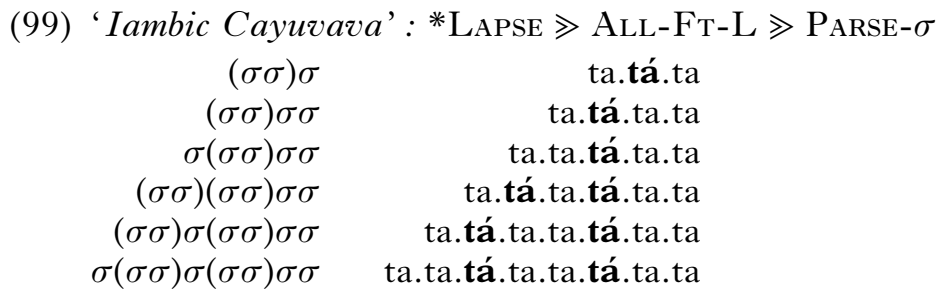

The resulting (unattested) pattern is highly similar to Cayuvava's, but with a twist: words of length $3 n$ have stress on the second syllable, rather than the initial.

In sum, we have seen three loosely aligned unidirectional patterns. In two of these $(100 \mathrm{a}, \mathrm{b})$ foot dominance is opposite to the starting edge X. Here persistence matters (depending on the relative ranking of PARSE- $\sigma$ and ALL-FT-Y). In the third pattern (100c), foot dominance matches the edge $\mathrm{X}$, and no distinction of persistence applies:

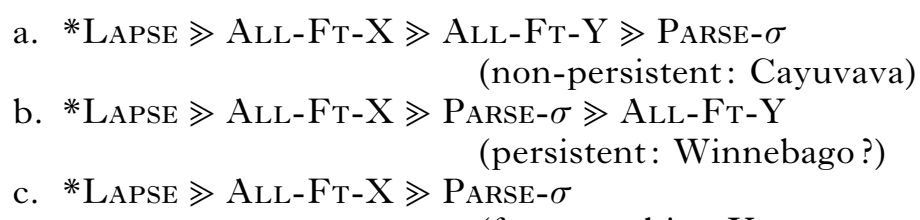

5.4.2 Unidirectional systems: strictly aligned. We now turn to 'strictly aligned' unidirectional ternary systems. This family differs minimally from the loosely aligned type by the promotion of an ALIGN-X constraint, with $\mathrm{X}$ being the edge at which the alternation starts. Analogously to loosely aligned systems, this branches out into three patterns. When foot dominance is opposite to the starting edge (trochees alternating from edge $\mathrm{R}$, or iambs from edge $\mathrm{L}$ ), persistence depends on the now familiar relative ranking of PARSE- $\sigma$ and ALL-FT-X ((101a) vs. (101b)). When foot dominance matches the starting edge, the persistence effect is automatic (101c). 
316 Nine Elenbaas and René Kager

(101) a. Align-X, *Lapse $\gg$ All-Ft-Y $\gg$ All-Ft-X $\gg$ Parse- $\sigma$

b. Align-X, *Lapse $\gg$ All-Ft-Y $\gg$ Parse- $\sigma \gg$ All-Ft-X

(non-persistent: $n / a$ )

c. Align-X, *Lapse $\gg$ All-Ft-Y $\gg$ Parse- $\sigma$ (persistent: Chugach)

(Estonian)

Pattern (101b), with persistent footing, is attested in iambic Chugach (see again §3).

A non-persistent variant of Chugach (101a) has the reverse ranking All-FT-X $\gg$ ParSe- $\sigma$ :

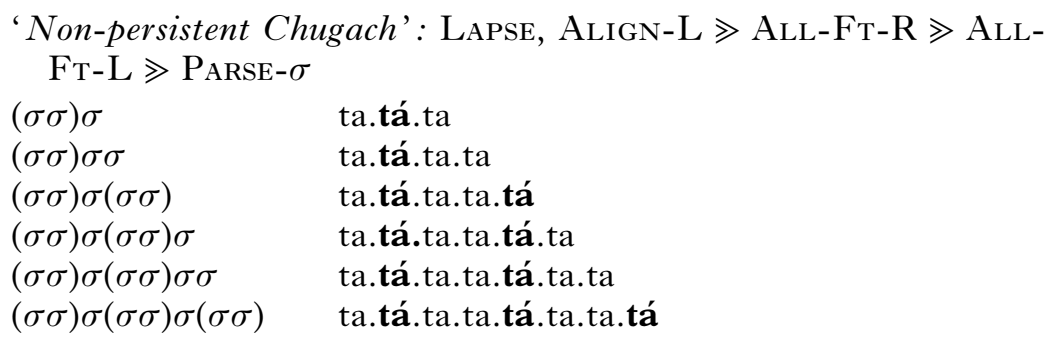

The persistent pattern with foot dominance matching the starting edge (101c) is attested in Estonian (Hint 1973, Prince 1980, Kager 1994, Hayes 1995). Main stress falls on the initial syllable, with a secondary stresses on every non-final syllable in position $3 n$ and a 'persistent' secondary stress on the penult in words of length $3 n+1$ syllables:

(103) Estonian: Align-L, *Lapse $\gg$ All-Ft $-\mathrm{R} \gg$ Parse- $\sigma$
a. (pí.mes).tav
'blinding'
b. (ré.te).(lì.le)
'ladder-ALL SG.'
c. (pí.mes).ta.(và.le) 'blinding-ILL SG'
d. (ó.sa).va.(mà.le).ki 'also more skilful-ABL SG'

Note that this rightward ternary pattern is not the only one possible in Estonian. It occurs in free variation with a rightward binary ('Pintupistyle') pattern.

5.4.3 Bidirectional systems. Finally, we turn to bidirectional ternary systems, which will all be dealt with in this section. Three types occur, which we repeat below (from (95c-e)).

(104) Bidirectional ternary systems
a. Align-X, *Lapse $\gg$ All-Ft-X $\gg$ Parse- $\sigma$ (simple, loosely aligned)
b. Align-X, *Lapse $\gg$ Align-Y $\gg$ All-Ft-X $\gg$ Parse- $\sigma$ (simple, strictly aligned)
c. Align-X, *Lapse $\gg$ Align-Y $\gg$ All-Ft-Y $\gg$ Parse- $\sigma$ (complex)

Here a foot is fixed at one edge (104a) or both edges (104b, c). Note that '(non-)persistence' is no longer an issue here, since only unidirectional 
Ternary rhythm and the lapse constraint 317

systems may ever display such a distinction. As we saw in $\$ 2$, double underparsing always occurs at the edge $\mathrm{Y}$ which is opposite to the starting edge $\mathrm{X}$. In a bidirectional system, where one foot is fixed at edge $\mathrm{Y}$, underparsing at that edge is precluded, leaving no room for a distinction of persistence.

These three patterns are the ternary analogues of bidirectional binary systems discussed in $\$ 5.2$. Then we found that bidirectionality was either 'simple' (Piro; (90b)) or 'complex' (Indonesian; (93c)). Ternarity brings a subdivision of simple bidirectionality into 'loosely' and 'strictly' aligned starting edges.

None of the three patterns in (104) is attested. We will first present the predicted patterns, and then discuss possible explanations for their lack of empirical attestation. Diagrams below are vertically aligned in such a way that the alternating pattern is maximally visualised.

First, we find a simple bidirectional pattern (104a), fixed at edge $\mathrm{X}$ and loosely aligned at the opposite edge $\mathrm{Y}$, where alternation starts. We depict both (trochaic) subpatterns, one with a single unparsed syllable at edge $\mathrm{Y}$, and another with two unparsed syllable at that edge.

(105) Align-X, *Lapse $\gg$ All-FT-X $\gg$ Parse- $\sigma$

(simple bidirectional, loosely aligned)

$$
\begin{array}{lr}
\mathrm{X}=\mathrm{R} & \mathrm{X}=\mathrm{L} \\
\text { ta.(tá.ta) } & (\text { tá.ta).ta } \\
\text { ta.ta.(tá.ta) } & (\text { tá.ta).(tá.ta) } \\
\text { ta.(tá.ta).(tá.ta) } & (\text { tá.ta).(tá.ta).ta } \\
\text { ta.ta.(tá.ta).(tá.ta) } & (\text { tá.ta).ta.(tá.ta).ta } \\
\text { ta.ta.(tá.ta).ta.(tá.ta) } & \text { (tá.ta).(tá.ta).(tá.ta).ta } \\
\text { ta.ta.(tá.ta).(tá.ta).(tá.ta) } & (\text { tá.ta).(tá.ta).ta.(tá.ta).ta } \\
\text { ta.ta.(tá.ta).ta.(tá.ta).(tá.ta) } & \text { (tá.ta).ta.(tá.ta).ta.(tá.ta).ta } \\
\text { ta.ta.(tá.ta).ta.(tá.tta).ta.(tá.ta) } & \text { (tá.ta).(tá.ta).(tá.ta).ta.(tá.ta).ta }
\end{array}
$$

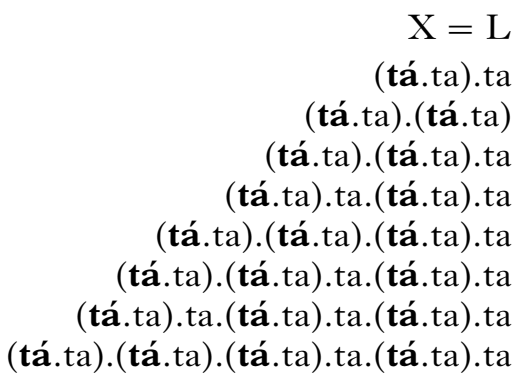

A second pattern (104b) differs from the first in being strictly aligned at both edges, with one edge taking priority over the other. Alternation is directed toward the 'dominant' edge $\mathrm{X}$, departing from the starting edge Y.

(106) Align-X, *Lapse $\gg$ Align-Y $\gg$ All-Ft-X $\gg$ Parse- $\sigma$

(simple bidirectional, strictly aligned)

$\mathrm{X}=\mathrm{R}, \mathrm{Y}=\mathrm{L}$

ta.(tá.ta)

(tá.ta).(tá.ta)

(tá.ta).ta.(tá.ta)

(tá.ta).(tá.ta).(tá.ta)

(tá.ta).ta.(tá.ta).(tá.ta)

(tá.ta).ta.(tá.ta).ta.(tá.ta)

(tá.ta).ta.(tá.ta).(tá.ta).(tá.ta)

(tá.ta).ta.(tá.ta).ta.(tá.ta).(tá.ta)
$\mathrm{X}=\mathrm{L}, \mathrm{Y}=\mathrm{R}$

(tá.ta).ta

(tá.ta).(tá.ta)

(tá.ta).ta.(tá.ta)

(tá.ta).(tá.ta).(tá.ta)

(tá.ta).ta.(tá.ta).(tá.ta)

(tá.ta).ta.(tá.ta).ta.(tá.ta)

(tá.ta).ta.(tá.ta).(tá.ta).(tá.ta)

(tá.ta).(tá.ta).ta.(tá.ta).ta.(tá.ta) 


\section{Nine Elenbaas and René Kager}

A third pattern again has feet strictly aligned at both edges, with priorisation of one over the other in trisyllabic words. But in contradistinction to the previous pattern, rhythm is directed away from the dominant edge $\mathrm{X}$. (The dominant edge $\mathrm{X}$ is the starting edge as well.).

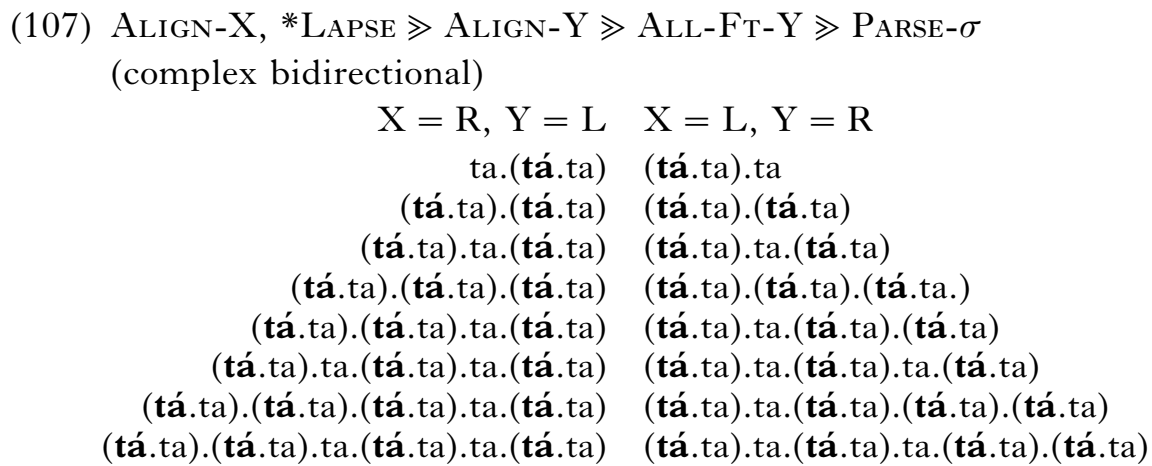

As observed above, none of these three patterns is attested in any natural languages currently known. More generally, no ternary systems are known that are of a bidirectional nature. What explains this gap in the typology? Here we have only speculations to offer, but we do believe that an explanation of the gap may involve a combination of three factors.

First, as compared to binary systems, ternary systems are typologically marked, apparently for their increased computational complexity. The constraint whose evaluation involves most computational complexity is ALL-FT-X, because of the gradient and accumulative nature of its violations. Note that the core constraint interaction underlying binarity, PARSE- $\sigma \gg$ All-FT-X, is computationally rather simple. The set of candidates to be evaluated by ALL-FT-X, having been drastically reduced by prior PARSE- $\sigma$, is homogeneous, with candidates having all the same density of parsing, and differing only in the position of feet. (See, for example, candidates $(6 \mathrm{a}-\mathrm{c})$.) In contrast, computation under the ternary constraint interaction *LAPSE $\gg$ ALL-FT-X $\gg$ PARSE- $\sigma$ is complex, since * LAPSE is a far less stringent constraint than PARSE- $\sigma$, passing a much larger and less homogeneous set of candidates to ALL-FT-X, including candidates with different densities of parsing. The eventual choice of binary $v s$. ternary alternation is then made almost entirely by ALL-FT-X.

Second, for independent reasons, bidirectional stress systems are typologically marked in comparison to unidirectional ones, even in binary systems (Hayes 1995). Lacking concrete evidence, we speculate that bidirectional parsing involves extra computational complexity as compared to unidirectional parsing. Bidirectionality has the additional problem of computing the interaction of a pre-installed foot at the edge with the stress train arriving at this landmark from the opposite edge.

Third, it has been suggested (Ishii 1996) that for ternary rhythm to become apparent to the linguist and the learner, a language must allow 
Ternary rhythm and the lapse constraint 319

fairly long words (minimally six syllables). The typological rareness of ternarity may thus be due to morphological factors (restrictions on stem size or stacked affixes). It is clear that for bidirectional ternarity to become apparent, a language needs even longer words (minimally eight syllables).

Finally, we note that the typological prediction of bidirectional ternarity is not exclusive to our rhythmic theory of anti-lapse. Any metrical theory that provides independent mechanisms for ternarity (to account for Cayuvava) and bidirectionality (to account for Piro) predicts that both tools can be freely combined, which amounts to bidirectional ternarity.

5.4.4 Underparsing and Non-Fin. One major issue must be addressed before we continue. There is a familiar puzzle in metrical theory related to overlap between means for ternarity (ternary feet, Weak Local Parsing, etc.) and extrametricality. The observation is that these devices never combine in any language in a way to generate languages with preantepenultimate stress. Why is this the case? Hammond's (1990) answer is that extrametricality and ternarity are due to a single representational device, which he called 'relativised extrametricality' (an unparsed syllable is licensed either at the end of a foot or at the end of a word).

Transposing the puzzle into OT, how do we avoid pre-antepenultimate stress due to the combined underparsing effects of NoN-FIN-FT ("no foot must be final in a PrWd') and *LAPSE $\gg$ ALL-FT-L ('stress every third syllable from the word end')? The answer is simple. Unlike extrametricality, the underparsing due to NoN-FIN maintains rhythmic "visibility' of the final syllable. Any unparsed syllable (whether at the edge of a domain or in the middle) counts as a weak beat in rhythmic evaluation by *LAPSE. Pre-antepenultimate stress is simply precluded by *LAPSE.

For example, a mini-typology of three constraints Non-Fin-FT, *LAPSE and ALL-FT-L, assuming trochaic parsing of a six-syllable string, has only two patterns:

$$
\begin{aligned}
& \text { a. Non-Fin-Ft, All-Ft-L } \gg * \text { Lapse }(\sigma \sigma \sigma) \sigma \sigma \sigma \sigma \\
& \text { (unbounded left edge) } \\
& \text { b. Non-Fin-FT, } * \text { LAPSE } \gg \text { AlL-FT-L }(\sigma \sigma \sigma) \sigma(\sigma \sigma) \sigma \\
& \text { (ternary leftward) }
\end{aligned}
$$

None of these rankings produces a pre-antepenultimate stress pattern $*(\sigma \sigma)(\sigma \sigma) \sigma \sigma$.

Interestingly, a grid-based theory of lapse avoidance based on *LAPSE invites an even more radical possibility, that of eliminating NON-FIN-FT altogether. Undominated *LAPSE allows maximally two successive weak beats at the right edge, prohibiting stress from falling further back than the third syllable from the end, thus predicting a 'three-syllable window'. Many languages (such as Modern Greek, Macedonian and Latin) strictly enforce the trisyllabic window by shifting stress rightward in enclitic contexts to keep stress within the window. Another typical three-syllablewindow effect is witnessed in languages like Pirahã (Everett 1988), which 


\section{Nine Elenbaas and René Kager}

displays a hierarchy of syllable quantity, with stress falling on the heaviest syllable within the three-syllable window (see Green 1994 for an analysis using a constituent-based anti-lapse constraint to enforce the window). Still other languages respect the three-syllable window by requiring the lexically accented syllable to fall within it (see Drachman et al. 1997 and Revithiadou 1999 for analyses of Modern Greek along these lines).

Assuming that trisyllabic window effects are due to undominated *LAPSE, it should now be clear that strict antepenultimate stress can be generated by pulling feet maximally leftward within the three-syllable window, that is, by *LAPSE $\gg$ ALL-FT-L $\gg$ PARSE- $\sigma$. This analysis would bring the long-desired unification of foot-to-edge non-finality and ternarity (Hammond 1990), simply by eliminating the former.

This elimination of Non-FIN-FT, attractive though it may seem due to its simplifying nature, leaves a number of questions unanswered. Most importantly, it is reported in the literature that some trisyllabic window languages are non-rhythmic in the sense that they lack secondary stresses (for example, Macedonian; Halle \& Kenstowicz 1991). Accordingly, in longer words there would be lapses in the material preceding the main stress, ruling out an analysis with an undominated *LAPSE constraint. Another prediction made under the current proposal is that secondary stress must be ternary in a syllable extrametricality language due to *LAPSE $\gg$ ALL-FT-L $\gg$ PARSE- $\sigma$ (essentially the ranking of Cayuvava, with or without left-edge alignment). We will not address these issues here, leaving them open for future research.

\subsection{Parsing theory: Parse-2 and *FtFt}

This section will briefly discuss the factorial typology of the 'parsing theory' of anti-lapse-constraints. The version of parsing theory that we will assume has the following constraints to model ternarity:

(109) Parse-2, Align-X/Y, All-Ft-X/Y, Parse- $\sigma$, *FtFt

Note that this set of constraints is similar to that of rhythmic theory (discussed earlier), the main difference being PARse-2 (Kager 1994) as the anti-lapse constraint instead of *LAPSE $:^{21}$

(110) Parse-2

One of two adjacent stress units (moras or syllables) must be parsed by a foot.

21 An alternative parsing-based anti-lapse constraint is suggested by Green \& Kenstowicz (1995):

(i) LAPSE

Adjacent unstressed moras or syllables must be separated by a foot boundary.

In comparison to PARSE-2, LAPSE has the additional effect of ruling out strings of unstressed stress units within a foot, thus prohibiting unbounded feet. This difference is irrelevant in the context of the present discussion, where undominated foot binarity is assumed. 
Ternary rhythm and the lapse constraint 321

With respect to the foot-repulsion constraint ${ }^{*} \mathrm{FTF}_{\mathrm{T}}$, we note that this is practically forced on the basis of the ternary pattern of Cayuvava. (See $\S 2.1$ for an analysis of Cayuvava that employs it, and $\$ 2.3$ for a review of Ishii's problematic attempt to dispense with it.) ${ }^{22}$

The factorial typology of parsing theory includes all core metrical patterns. However, in two respects it overgenerates to a far greater extent than rhythmic theory (*LAPSE). First, it overgenerates in predicting patterns with long lapses, of either three week beats (underlined) or four weak beats (double underlined), as in (111):

(111) *FtFt, Align-X $\gg$ Parse- $2 \gg$ All-Ft-L

(ternarity with long lapses)

$$
\begin{aligned}
& \mathrm{X}=\mathrm{L} \quad \mathrm{X}=\mathrm{R} \\
& \text { (tá.ta).ta ta.(tá.ta) } \\
& \text { (tá.ta).ta.ta ta.ta.(tá.ta) } \\
& \text { (tá.ta).ta.(tá.ta) (tá.ta).ta.(tá.ta) } \\
& \text { (tá.ta).ta.(tá.ta).ta (tá.ta).ta.ta.(tá.ta) } \\
& \text { (tá.ta).ta.(tá.ta).ta.ta (tá.ta).ta.ta.ta..(tá.ta) } \\
& \text { (tá.ta).ta.(tá.ta).ta.(tá.ta) (tá.ta).ta.(tá.ta).ta.(tá.ta) } \\
& \text { (tá.ta).ta.(tá.ta).ta.(tá.ta).ta (tá.ta).ta.(tá.ta).ta.ta.(tá.ta) } \\
& \text { (tá.ta).ta.(tá.ta).ta.(tá.ta).ta.ta (tá.ta).ta.(tá.ta).ta.ta.ta.(tá.ta) }
\end{aligned}
$$

In contrast, rhythmic theory is simply unable to generate such long lapses since it has no foot-repulsion constraint. The only way to generate a rhythmic pattern is a ranking *LAPSE $\gg$ ALL-FT-X, but this restricts lapses to two weak beats.

However, a second kind of overgeneration by parsing theory is even more serious. Strange non-directional patterns result, as in the trochaic mirror-image parsings below:

(112) Parse-2, *FtFT $\gg$ All-Ft-X

(non-directional ternarity)

$$
\begin{array}{cc}
\mathrm{X}=\mathrm{L} & \mathrm{X}=\mathrm{R} \\
\text { (tá.ta).ta } & \text { ta.(tá.ta) } \\
\text { ta.(tá.ta).ta } & \text { ta.(tá.ta).ta } \\
\text { (tá.ta).ta.(tá.ta) } & \text { (tá.ta).ta.(tá.ta) } \\
\text { (tá.ta).ta.(tá.ta).ta } & \text { ta.(tá.ta).ta.(tá.ta) } \\
\text { ta.(tá.ta).ta.(tá.ta).ta } & \text { ta.(tá.ta).ta.(tá.ta).ta } \\
\text { (tá.ta).ta.(tá.ta).ta.(tá.ta) } & \text { (tá.ta).ta.(tá.ta).ta.(tá.ta) } \\
\text { (tá.ta).ta.(tá.ta).ta.(tá.ta).ta } & \text { ta.(tá.ta).ta.(tá.ta).ta.(tá.ta) } \\
\text { ta.(tá.ta).ta.(tá.ta).ta.(tá.ta).ta } & \text { ta.(tá.ta).ta.(tá.ta).ta.(tá.ta).ta }
\end{array}
$$

Patterns of this kind are totally unattested among the languages of the world. The remarkable property is the lack of consistent directionality:

${ }^{22}$ We leave out of consideration the issue of how parsing theory and rhythmic theory compare in their use of non-finality constraints. We saw that rhythmic theory is able to do without Non-FIN-FT in the analysis of Cayuvava $(\$ 2.2)$, while parsing theory still requires it $(\$ 2.3)$. However, the issues raised at the end of the previous subsection prohibit a strong position on this. 


\section{Nine Elenbaas and René Kager}

there is no unique edge ( $\mathrm{L}$ or $\mathrm{R}$ ) towards which the pattern is oriented. Note the lack of consistent left-edge alignment or right-edge alignment. Upon closer inspection, it appears that each pattern is composed of three sub-patterns, one for each of three types of syllable length.

In words of $3 n+1$ or $3 n+2$ syllables, PARSE- 2 and $*_{\mathrm{TTFT}}$ uniquely determine both number of feet and their position, selecting perfectly symmetrical, even-spaced parses. For these word lengths, the parsings in the lefthand and righthand pyramids of (112) are identical.

$$
\begin{array}{cl}
\text { a. } 3 n+1: \text { doubly misaligned, } \mathrm{n} \text { feet } \\
4 \sigma & \text { ta.(tá.ta).ta } \\
7 \sigma & \text { ta.(tá.ta).ta.(tá.ta).ta } \\
10 \sigma & \text { ta.(tá.ta).ta.(tá.ta).ta.(tá.ta).ta } \\
\text { b. } 3 n+2: & \text { doubly aligned, } \mathrm{n}+1 \text { feet } \\
5 \sigma & \text { (tá.ta).ta.(tá.ta) } \\
8 \sigma & \text { (tá.ta).ta.(tá.ta).ta.(tá.ta) } \\
11 \sigma & \text { (tá.ta).ta.(tá.ta).ta.(tá.ta).ta.(tá.ta) }
\end{array}
$$

Foot parsing would be identical if iambs (instead of trochees) were assumed, since parsing-based constraints are blind to the spacing of beats on the grid. Observe that any 'reshuffling' of feet (while keeping their number constant) would run into additional violations of $*_{\mathrm{FT}} \mathrm{FT}$. Here ALL-FT-X simply has no chance of becoming involved.

But in words of $3 n$ syllables, the pair PARSE-2, *FTFT no longer uniquely determines foot distribution, leaving a choice of two patterns for each string. Indeterminacies are resolved by ALL-FT-X, which orientates feet towards the edge $\mathrm{L}$ or $\mathrm{R}$.

$$
\begin{aligned}
& \text { a. } 3 n: \text { left-aligned } \\
& 3 \sigma \text { (tá.ta).ta } \\
& 6 \sigma \text { (tá.ta).ta.(tá.ta).ta } \\
& 9 \sigma \text { (tá.ta).ta.(tá.ta).ta.(tá.ta).ta } \\
& \text { b. } 3 n: \text { right-aligned } \\
& 3 \sigma \text { ta.(tá.ta) } \\
& 6 \sigma \text { ta.(tá.ta).ta.(tá.ta) } \\
& 9 \sigma \text { ta.(tá.ta).ta.(tá.ta).ta.(tá.ta) }
\end{aligned}
$$

Variations on these non-directional patterns arise when alignment constraints come into play. In contrast to the previous patterns, these aligned patterns have one 'anchored' stress, but they still lack consistent directionality of remaining stresses.

In sum, parsing theory overgenerates in generating patterns that are categorically absent in languages currently known from the metrical literature. Both long-lapse and non-directional patterns are due to in-

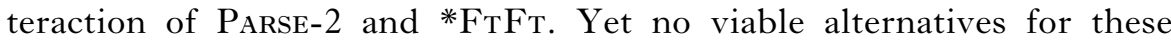


Ternary rhythm and the lapse constraint 323

constraints seem to be available in parsing theory. First, PARSE- 2 is crucial in generating the 'persistent' patterns of Estonian and Chugach. It limits inter-foot distance (as well as distance between a foot and the word edge) to one syllable. Second, *FтFт is crucial in generating the Cayuvava pattern, where it serves to block 'persistent footing'.

\subsection{Rule theory: Weak Local Parsing}

This final section discusses the factorial typology of a rule-based theory of ternarity, assuming Weak Local Parsing (WLP), and a persistent footing parameter (Hayes 1995). This typology arises from the permutation of its parameter values.

First, a Foot Parsing Locality Parameter is defined by Hayes (1995: 308):

\section{(115) Foot Parsing Locality Parameter}

a. Strong Local Parsing

When a foot has been constructed, align the window for further parsing at the next unfooted syllable (unmarked value of the parameter).

b. Weak Local Parsing

When a foot has been constructed, align the window for further parsing by skipping over a light syllable, where possible (marked value of the parameter).

Second, persistent footing is defined by Hayes (1995: 115). It has two provisions, the second of which is crucial in dealing with ternarity.

(116) Persistent footing

a. Single stray syllables are adjoined to existing feet if the result is well-formed.

b. Otherwise, sequences of stray syllables may be converted into feet.

This is a 'parameter' to the extent that it applies on a language-specific basis.

Next, we have other parametric choices relevant to parsing, such as:

(117) a. Iterativity of foot parsing (iterative or non-iterative).

b. Directionality of foot parsing (starting at left edge or starting at right edge).

c. Foot type (syllabic trochee, moraic trochee, iamb).

d. Extrametricality (syllable, foot). 


\section{Nine Elenbaas and René Kager}

Note that the pattern of a single word may be defined by multiple rules. For example, stress patterns in Piro words of more than four syllables arise by building a single (non-iterative) foot at the right edge, while multiple feet are built starting at the left edge. Extrametricality is also relevant to ternarity, as will be clear from the discussion of Cayuvava in $\S 2$.

WLP theory generates roughly the same patterns as OT-based rhythmic theory. It lacks the ominous non-directional patterns of parsing theory (see previous section), but nevertheless it resembles parsing theory in generating 'long-lapsed' patterns. This is understandable from the fact that a foot-repulsion mechanism is part of both theories. Clearly WLP and * FTFT serve the similar function of keeping space between feet.

In unidirectional patterns, non-persistent footing produces lapses at the right edge of three weak beats. With the help of extrametricality, lapses may be extended with a fourth syllable:

(118) Iterative feet from left to right, WLP, non-persistent without extrametrically

(tá.ta).ta
(tá.ta).ta.ta
(tá.ta).ta.(tá.ta)
(tá.ta).ta.(tá.ta).ta
(tá.ta).ta.(tá.ta).ta.ta
(tá.ta).ta.(tá.ta).ta.(tá.ta)
(tá.ta).ta.(tá.ta).ta.(tá.ta).ta
(tá.ta).ta.(tá.ta).ta.(tá.ta).ta.ta
with extrametricality

(tá.ta).ta

(tá.ta).ta.ta

(tá.ta).ta.ta.ta

(tá.ta).ta.(tá.ta).ta

(tá.ta).ta.(tá.ta).ta.ta

(tá.ta).ta.(tá.ta).ta.ta.ta

(tá.ta).ta.(tá.ta).ta.(tá.ta).ta

(tá.ta).ta.(tá.ta).ta.(tá.ta).ta.ta

In bidirectional patterns, a difference between approaches based on WLP and ${ }^{*} \mathrm{FTF}_{\mathrm{T}}$ becomes apparent: WLP always skips a syllable after a foot assigned on the same iteration, and cannot 'look ahead' to leave unparsed a syllable before a foot that is approaches (in the direction of iteration). Therefore, the maximal interbeat lapse in WLP theory is three weak beats (while lapses are maximally four weak beats in *FTFT theory; cf. (111)).

(119) Single foot at edge $X$, iterative feet starting at edge $Y, W L P$, nonpersistent

$\mathrm{X}=\mathrm{R}$

ta.(tá.ta)

(tá.ta).(tá.ta)

(tá.ta).ta.(tá.ta)

(tá.ta).ta.ta.(tá.ta)

(tá.ta).ta.(tá.ta).(tá.ta)

(tá.ta).ta.(tá.ta).ta.(tá.ta)

(tá.ta).ta.(tá.ta).ta.ta.(tá.ta)

(tá.ta).ta.(tá.ta).ta.(tá.ta).(tá.ta)

$$
\mathrm{X}=\mathrm{L}
$$

(tá.ta).ta

(tá.ta).(tá.ta)

(tá.ta).ta.(tá.ta)

(tá.ta).ta.ta.(tá.ta)

(tá.ta)(tá.ta).ta.(tá.ta)

(tá.ta).ta.(tá.ta).ta.(tá.ta)

(tá.ta).ta.ta.(tá.ta).ta.(tá.ta)

(tá.ta).(tá.ta).ta.(tá.ta).ta.(tá.ta) 
Ternary rhythm and the lapse constraint 325

The typological problem for persistent footing theory is that it cannot universally rule out the long-lapse patterns (118)-(119), since languages must be able to select persistent footing on a Parametric basis. Persistent footing cannot be promoted to universality, since that would obliterate the very typological distinction that its parametric status was meant to capture. It is precisely the difference in metrification between Cayuvavatype ternarity (where sequences of unparsed syllables are allowed) and Chugach-type ternarity (where such strings are avoided) that motivates persistence as a language-specific option (disabling its status as a universal output constraint).

Does this typological objection of overgeneration generalise to all versions of rule theory? Specifically, does the problem still hold under the assumption of a universal anti-lapse output filter to trim back excessive underparsing by foot-construction rules? While such approaches are technically feasible, they run into severe conceptual problems, undermining assumptions about rule application that are essential to rule theory. Below we will argue that two natural extensions of Hayes's theory with an anti-lapse filter have serious conceptual drawbacks.

First, one might attempt to build the lapse-avoiding filter into the footconstruction rules. For example, *LAPSE might be installed as an antilapse filter on foot construction, overruling the application of WLP whenever it would produce a long lapse in the remaining string. This approach fails wherever a long string of unparsed syllables lies ahead of the local context of application. Then any application of footing leaves a long lapse in the output, regardless of whether WLP or SLP is chosen. Any local checks on the applicability of WLP must therefore look ahead, taking into account the parsing of the remaining syllables in the string. This is illustrated in (120). Parsing is rightward, while the output of every step of foot construction (WLP or SLP) is indicated.

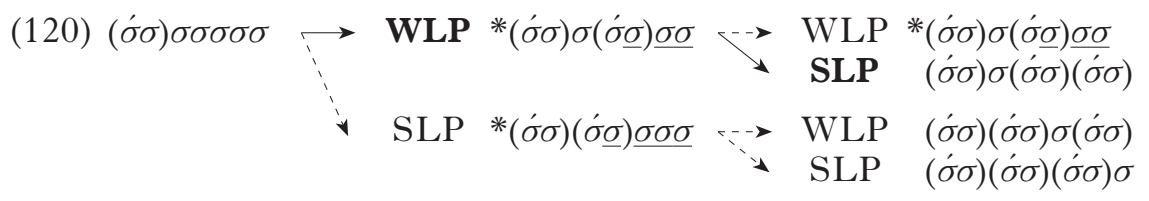

Arrows with solid lines indicate the derivation to be taken; while broken lines are alternative to be avoided. Note that the decision to assign a foot under WLP on the first step cannot be based on the local output at this stage (as both intermediate outputs contain lapses), and must take into account the result of foot construction on the final step (where an output is available that satisfies the anti-lapse filter). 'Look ahead' cannot be avoided, showing that the anti-lapse filter cannot act as a local condition on individual application of foot construction.

A second attempt to save Hayes' theory involves extending it with a universal anti-lapse filter (identical to *LAPSE) as a post hoc device, filtering out any long-lapse outputs such as (118)-(119). For example, any 


\section{Nine Elenbaas and René Kager}

violation of *LAPSE in the output of iterative foot construction might activate the obligatory application of persistent footing, regardless of the parametric value for persistent footing selected by a language. While technically feasible, this idea is conceptually dubious. Most importantly, *LAPSE is not organically connected with the rhythmic conditions built into the parsing procedure itself, such as iterativity and the skipping of maximally one syllable by WLP. Nor is * LAPSE connected with the persistent footing parameter, which it is able to overrule. The result is fragmentation of explanatory principles, a situation generally known as the CONSPIRACY problem (Kisseberth 1970). In contrast, a constraintbased theory of rhythm has the considerable advantage of capturing such connections.

A severe typological problem for a theory that kills off the long-lapse patterns (118)-(119) by means of a universal output filter is the existence of unbounded languages, which violate it. Accordingly, the scope of 'universal' *LAPSE must be limited to the class of languages that have iterative foot-construction rules. This is a brute-force stipulation lacking any explanatory force. In contrast, a theory like ours, employing a universal yet violable anti-lapse constraint, captures the typological distinction between bounded and unbounded systems by reranking of the constraints All-FT-X, *LAPSE and PARSE- $\sigma$. Here the generalisation that long lapses are avoided only in 'bounded' languages follows naturally from constraint interaction.

In sum, OT improves over rule theory not only conceptually, avoiding the fragmentation of rhythmic generalisations ('parsing' $v s$. 'repair'), but also typologically, by universally avoiding the generation of long lapses in bounded systems.

\section{Conclusions}

Our principal findings are the following. First, we have shown that OT allows an elegant and principled account of rhythmic ternarity, a phenomenon that causes severe complications in rule-based metrical theory. The core constraint interaction underlying ternarity (*LAPSE $\gg$ ALL-FT-X $\gg$ PARSE- $\sigma$ ) accounts for languages with uniform ternarity (Cayuvava, Chugach Alutiiq) and is easily extendable to languages where rhythmic ternarity and binarity co-occur (Winnebago, Estonian). Typological variation within the class of ternary rhythmic systems is accounted for by reranking a small set of constraints with respect to word-to-foot alignment (Align-X).

The theory of ternarity proposed here involves an anti-lapse constraint, *LAPSE, ruling out weak beats that are non-adjacent to strong beats or word edges. *LAPSE receives independent support as a universal constraint from two languages with local ternary patterns (Sentani and Finnish), where it trims back underparsing effects of quantitative constraints. 
Ternary rhythm and the lapse constraint 327

Comparing the grid-based (*LAPSE) and the constituent-based (PARSE2) format of the anti-lapse constraint, we found the former to be empirically superior, both in the analysis of individual systems (Cayuvava, Sentani) and in providing a more restrictive factorial typology. In contrast, parsing theory faces a serious overgeneration problem by predicting non-directional patterns stemming from the combination of PARSE-2 and the foot-repulsion constraint *FTFT.

Finally, we have demonstrated that our typological results cannot be duplicated under rule theory, because of the intrinsic parametric status of the lapse-avoiding mechanism ('persistent footing').

\section{REFERENCES}

Alber, Birgit (1997). Quantity sensitivity as the result of constraint interaction. In G. E. Booij \& J. van der Weijer (eds.) Phonology in progress: progress in phonology. The Hague: Holland Academic Graphics. 1-45.

Allison, E. (1979). The phonology of Sibutu Sama: a language of the Southern Philippines. In C. Edrial-Luzares \& A. Hale (eds.) Studies in Philippine Languages 3:2. Linguistic Society of the Philippines \& Summer Institute of Linguistics.

Anttila, Arto (1995). Deriving variation from grammar: a study of Finnish genitives. Ms, Stanford University. Available as ROA-63 from the Rutgers Optimality Archive.

Anttila, Arto (1997). Variation in Finnish phonology and morphology. PhD dissertation, Stanford University.

Beckman, Jill (1997). Positional faithfulness, positional neutralisation and Shona vowel harmony. Phonology 14. 1-46.

Carlson, Lauri (1978). Word stress in Finnish. Ms, MIT.

Cohn, Abigail (1989). Stress in Indonesian and bracketing paradoxes. NLLT 7. 167-216.

Cohn, Abigail \& John McCarthy (1994). Alignment and parallelism in Indonesian phonology. Ms, Cornell University \& University of Massachusetts, Amherst. Available as ROA-25 from the Rutgers Optimality Archive.

Drachman, Gaberell, René Kager \& Angeliki Malikouti-Drachman (1997). Greek allomorphy: an optimality account. In G. Drachman, A. Malikouti-Drachman, J. Fykias \& C. Klidi (eds.) Greek linguistics 95. Vol. 1. Graz: W. Neugebaur. 151-160.

Dresher, B. Elan \& Aditi Lahiri (1991). The Germanic foot: metrical coherence in Old English. LI 22. 251-286.

Elenbaas, Nine (1996). Ternary rhythm in Sentani. In C. Cremers \& M. den Dikken (eds.) Linguistics in the Netherlands 1996. Amsterdam: Benjamins. 61-72.

Elenbaas, Nine (1999). A unified account of binary and ternary stress : considerations from Sentani and Finnish. PhD dissertation, Utrecht University.

Everett, Daniel L. (1988). On metrical constituent structure in Pirahã phonology. NLLT 6. 207-246.

Furby, Christine (1974). Garawa phonology. Canberra: Australian National University.

Goldsmith, John (ed.) (1995). The handbook of phonological theory. Cambridge, Mass. \& Oxford: Blackwell.

Green, Thomas (1994). The stress window in Pirahã: a reanalysis of rhythm in Optimality Theory. Ms, MIT.

Green, Thomas \& Michael Kenstowicz (1995). The Lapse constraint. Ms, MIT.

Hale, Kenneth \& Josie White Eagle (1980). A preliminary metrical account of Winnebago accent. If AL 46. 117-132. 


\section{Nine Elenbaas and René Kager}

Halle, Morris (1990). Respecting metrical structure. NLLT 8. 149-176.

Halle, Morris \& William Idsardi (1995). General properties of stress and metrical structure. In Goldsmith (1995). 403-443.

Halle, Morris \& Michael Kenstowicz (1991). The Free Element Condition and cyclic versus noncyclic stress. LI 22. 457-501.

Halle, Morris \& Jean-Roger Vergnaud (1987). An essay on stress. Cambridge, Mass. : MIT Press.

Hammond, Michael (1990). Deriving ternarity. Ms, University of Arizona, Tucson.

Hansen, K. \& L. Hansen (1969). Pintupi phonology. Oceanic Linguistics 8. 153-170.

Hanson, Kirstin \& Paul Kiparsky (1996). A parametric theory of poetic meter. $\operatorname{Lg} \mathbf{7 2}$. 287-335.

Hayes, Bruce (1980). A metrical theory of stress rules. PhD dissertation, MIT. Distributed 1981, Indiana University Linguistics Club.

Hayes, Bruce (1995). Metrical stress theory: principles and case studies. Chicago: University of Chicago Press.

Hewitt, Mark (1992). Vertical maximization and metrical theory. PhD dissertation, Brandeis University.

Hint, Mati (1973). Eesti keele sonafonoloogia. [Word phonology of Estonian.] Vol. 1. Tallinn: Eesti NSV Teaduste Akadeemia.

Hung, Henrietta (1994). The rhythmic and prosodic organisation of edge constituents. $\mathrm{PhD}$ dissertation, Brandeis University. Available as ROA-24 from the Rutgers Optimality Archive.

Ishii, Toru (1996). An optimality theoretic approach to ternary stress systems. In B. Agbayani \& N. Harada (eds.) Proceedings of the South Western Optimality Theory Workshop (SWOT II). UCI Working Papers in Linguistics 2. 95-111.

Kager, René (1992). Shapes of the generalized trochee. WCCFL 11. 298-312.

Kager, René (1993). Alternatives to the iambic-trochaic law. NLLT 11. 381-432.

Kager, René (1994). Ternary rhythm in alignment theory. Ms, Utrecht University. Available as ROA-35 from the Rutgers Optimality Archive.

Kager, René (1995). On foot templates and root templates. In M. den Dikken \& K. Hengeveld (eds.) Linguistics in the Netherlands 1995. Amsterdam: Benjamins. $125-138$

Kager, René (1997). Generalized alignment and morphological parsing. Rivista di Linguistica 9. 245-282.

Key, Harold (1961). Phonotactics of Cayuvava. IfAL 27. 143-150.

Key, Harold (1967). Morphology of Cayuvava. The Hague: Mouton.

Kiparsky, Paul (1991). Catalexis. Ms, Stanford University \& Wissenschaftskolleg zu Berlin.

Kisseberth, Charles W. (1970). On the functional unity of phonological rules. LI 1. 291-306.

Leer, Jeff (1985). Prosody in Alutiiq. In M. Krauss (ed.) Yupik Eskimo prosodic systems : descriptive and comparative studies. Fairbanks: Alaska Native Language Center. 77-133.

Levin, Juliette (1985). Evidence for ternary feet and implications for a metrical theory of stress rules. Ms, University of Texas at Austin.

Levin, Juliette (1988). Generating ternary feet. Texas Linguistic Forum 29. 97-113.

Liberman, Mark (1975). The intonational system of English. PhD dissertation, MIT.

Liberman, Mark \& Alan Prince (1977). On stress and linguistic rhythm. LI 8. 249-336.

McCarthy, John \& Alan Prince (1993a). Prosodic morphology I : constraint interaction and satisfaction. Ms, University of Massachusetts, Amherst \& Rutgers University.

McCarthy, John \& Alan Prince (1993b). Generalized alignment. Yearbook of Morphology 1993. 79-153. 
Ternary rhythm and the lapse constraint 329

Matteson, Esther (1965). The Piro (Arawakan) language. Berkeley: University of California Press.

Miner, Kenneth (1979). Dorsey's Law in Winnebago-Chiwere and Winnebago accent. If AL 45. 25-33.

Miner, Kenneth (1981). Metrics, or Winnebago made harder. IfAL 47. 340-342.

Miner, Kenneth (1989). Winnebago accent: the rest of the data. Anthropological Linguistics 31. 148-172.

Oates, William \& Lynette Oates (1964). Gugu-Yalanji linguistic and anthropological data. In W. Oates \& L. Oates. Gugu-Yalanji and Wik-Mungan language studies. Canberra: Australian Institute of Aboriginal Studies. 1-17.

Osborn, Henry A. (1966). Warao I: phonology and morphophonemics. IfAL 32. 108-123.

Prince, Alan (1980). A metrical theory for Estonian quantity. LI 11. 511-562.

Prince, Alan (1983). Relating to the grid. LI 14. 19-100.

Prince, Alan \& Paul Smolensky (1993). Optimality Theory: constraint interaction in generative grammar. Ms, Rutgers University \& University of Colorado, Boulder.

Revithiadou, Anthi (1999). Headmost accent wins : head dominance and ideal prosodic form in lexical accent systems. $\mathrm{PhD}$ dissertation, University of Leiden.

Rice, Curtis (1992). Binarity and ternarity in metrical theory : parametric extensions. $\mathrm{PhD}$ dissertation, University of Texas at Austin.

Selkirk, Elisabeth (1984). Phonology and syntax: the relation between sound and structure. Cambridge, Mass.: MIT Press.

Steriade, Donca (1995). Underspecification and markedness. In Goldsmith (1995). $114-174$.

Susman, Amelia (1943). The accentual system of Winnebago. PhD dissertation, Columbia University, New York.

Zoll, Cheryl (1997). Conflicting directionality. Phonology 14. 263-286. 